IBAD Sosyal Bilimler Dergisi

IBAD Journal of Social Sciences

dergipark.org.tr/ibad

IBAD, 2021; (9): 117-142

DOI: $10.21733 /$ ibad.793183

Özgün Araştırma / Original Article

\title{
Barselona Sözleşmesi Kapsamında Akdeniz ve Kıyılarının Korunmasında Çevresel İşbirliğinin Önemi
}

\section{The Importance of the Environmental Cooperation in Protection of the Mediterranean Sea and its Coasts through the Barcelona Convention}

\author{
İmam Bakır Kanl1 ${ }^{*}$ \\ Nahide Nur Falcıoğlu² \\ * Sorumlu yazar \\ Corresponding author
}

${ }^{1}$ Doç. Dr., Marmara Üniversitesi, Türkiye,

Assoc. Prof. Dr., Marmara University, Turkey,

bkanli@yahoo.com,

ORCID ID 0000-0002-5715-8752

${ }^{2}$ Öğrenci, Marmara Üniversitesi, Türkiye,

Student, Marmara University, Turkey,

nahidefalcioglu@marun.edu.tr,

ORCID ID 0000-0003-1539-8093

Makale geliş tarihi / First received : 10.09.2020

Makale kabul tarihi / Accepted : : 27.12.2020

Bilgilendirme / Acknowledgement:

Yazarlar aşağı daki billgillen dirmeleri yapmaktadırlar:

1- Araştırmacıların katkı oranı eşittir.

2- Bu çalışma, 1-2 Eylül 2020 tarihleri arasında İstanbul'da gerçekleştirilen, $5^{\text {th }}$ International Scientific Research ECongress (IBAD - 2020)'de sözlü sunum olarak sunulmuştur.

3- Makalenin yazarları arasında çıkar çatışması bulunmamaktadır.

4- Makalemizde etik kurulu izni ve/veya yasal/özel izin alınmasını gerektiren bir durum yoktur.

5- Bu makalede araştırma ve yayın etiğine uyulmuştur.

This article was checked by iThenticate. Similarity Index $14 \%$

\section{Atıf bilgisi / Citation:}

Kanlı, İ.B., Falcıoğlu, N.N. (2021). Barselona Sözleşmesi kapsamında Akdeniz ve kıyılarının korunmasında çevresel işbirliğinin önemi. IBAD Sosyal Bilimler Dergisi, (9), 117-142. 


\section{ÖZ}

Avrupa, Asya ve Afrika kıtalarının kesişim bölgesinde yer alan stratejik önemi haiz olan Akdeniz Havzası, gerek ulaşım modlarının odak merkezinde yer alması sebebiyle ticaret bağlamında, gerek deniz altı enerji potansiyeli ve gerekse insanoğlunun bu havza üzerinde gerçekleştirdiği kirletici faaliyetler nedeniyle küresel gündemdeki yerini hep korumuştur. Havzanın bu çekici yapısı sadece ticaretin gelişmesinde değil aynı zamanda sanayinin de bölgede yoğunlaşmasında önemli rol oynamıştır. Bu yoğunlaşmaların olumsuz sonuçlarından birisi, öncelikle yerel ölçekte kıyıların kirlenmesi, sonrasında ise Akdeniz Havzasını bütünüyle etkileyebilecek bir çevre kirliliği ile karşı karşıya kalması olmuştur. Plansız kentleşme ve sanayileşmeye koşut olarak, deniz taşımacilığı esnasında yaşanan kazaların neden olduğu atıklar ile petrol ve türevlerinin ekosisteme zarar vermesi de havzanın karşı karşıya kaldığı sorunların artmasına, çözüm süreçlerinin zorlaşmasına neden olmaktadır. Böylesine zengin bir sosyo-ekonomik ekosistemi barındıran alanın pek çok ülkeye ev sahipliği yaptığı düşünüldüğünde, çözümlerin de ancak çoklu işbirliği unsurları ile çözülebileceği kaçınılmaz olmaktadır. Bu bağlamda 1976'da imzalanan Barselona Sözleşmesi kirliliğin önlenmesi konusundaki deniz ticaretine ilişkin hususları ele alması açısından son derece önemli adım olmuştur. İşte bu çalışmanın konusu Akdeniz Havzasında yer alan ülkelerin bölge ölçeğinde oluşturacakları inisiyatif ve çalışmaları Barselona Sözleşmesi çerçevesinde ele almasıdır. İklim değişikliğine uyumlu ve yerleşimleri güvenli olan ülkelerin nasıl bir politika inşa etmesi gerektiğine ilişkin öneri sunması, Akdeniz ve kıyılarının korunması konusunda gelecek çalışmalara yön vermesi ve literatürde tamamlayıcı unsur olması çalışmayı önemli kılmaktadır. Bu bağlamda çalışmanın amacı Barselona Sözleşmesi kapsamı içerisinde Akdeniz'in korunmasına yönelik politikaların etkinliğinin analiz edilmesidir. Çalışmada akitin uygulama alanları Akdeniz'de Özel Koruma Alanları ve Biyolojik Çeşitliliğe İlişkin Protokolü çerçevesinde İspanya ve Türkiye ülkeleri özelinde sinırlandırılmıştır. Bu çalışmada nitel araştırma yöntemi benimsenmiş; literatür taraması yapılarak, uluslararası kurum ve kuruluşlarının yayımladığı teknik raporlardan faydalanılmıştır. Çalışmada, elde edilen bulgular üzerinden yapılan değerlendirme ve analiz sonucunda Türkiye'nin Akdeniz Havzasındaki bölgesel çalışmalarda avantajlar sunduğu anlaşılmıştır. Barselona Sözleşmesi'nin hedefleri doğrultusunda güç sağlamasında Türkiye'nin büyük ölçüde yardımlar sağladığı gözlemlenmiştir.

Anahtar Kelimeler: Akdeniz, Akdeniz Havzas1, Barselona Sözleşmesi, çevre, çevresel işbirliği.

\section{ABSTRACT}

The Mediterranean Basin, located on the intersection of the continents Europe, Asia and Africa, has always been on the global agenda due to its location in the centre of transportation modes, its underwater energy potential and the polluting activities carried out by people on this basin. The attractive structure of the basin played an important role not only in the development of trade but also in the concentration of industry in the region. First of all, one of the negative consequences of these concentrations was the pollution of the coasts at the local scale, and then an environmental pollution that could affect the entire Mediterranean Basin. Parallel to unplanned urbanisation and industrialisation, the toxic matter and oil released during maritime transportation and accidents damage the ecosystem, cause problems faced by the basin to be more hazardous and the solution processes to be more difficult. Considering that the area, which has such a rich socioeconomic ecosystem, is home to many countries, it is inevitable that solutions can only be made with multiple cooperation elements. In this context, the Barcelona Convention signed in 1976 has been a very important step in terms of addressing the issues related to maritime trade in the prevention of pollution. The subject of this study is to deal with the initiatives and activities of the countries at the region scale through the Barcelona Convention. The fact that it offers suggestions on what kind of policies should be made by countries that are compatible with climate change and have safe settlements, guides future studies on the protection of the Mediterranean and its coasts, and it is a complementary element in the literature. In this context, the purpose of the study is to analyse the effectiveness of policies for the protection of the Mediterranean within the scope of the Barcelona Convention. Application areas for Specially Protected Areas in the study contracts and the countries of Spain and Turkey in the framework of the Protocol on Biological Diversity in the Mediterranean in particular has been limited. In this study, qualitative research method was adopted; literature review was performed and technical reports published by international institutions and organisations were used. In the study, as a result of the evaluation and analysis made on the findings obtained, it is clear that Turkey has contributed to the works performed in the Mediterranean Basin at regional level. Turkey has been observed to provide substantial contribution in line with the objectives of the convention.

Keywords: The Mediterranean Sea, the Mediterranean Basin, Barcelona Convention, environment, environmental cooperation. 


\section{GİRiş}

Akdeniz Havzası; Asya, Avrupa ve Afrika kıtalarını içine alan farklı sosyal, ekonomik, kültürel ve çevresel toplulukların odağındadır. Englehardt'ın çalışmasından aktaran Güneş, (2016, s. 12) medeniyetlerin hayat alanı Akdeniz'i, yakın tarihte Ortadoğu petrolünü Avrupa'ya taşıyan, Hint Okyanusu'ndaki taşımacılığı dünyanın her noktasıyla bir araya getiren, Karadeniz'deki ticaretin iktisadi boyutunu farklı boyutlara yönlendiren, Kuzey Atlantik Antlaşması Örgütü'nü (NATO) Uzakdoğu ve Ortadoğu ile yakınlaştıran havza olarak tanımlar. Bugün yaşanan siyasi, ekonomik, enerji alanındaki gelişmeler bölgenin önemini daha da artırmıştır. Özellikle enerji taşımacılığ konusunda Doğu Akdeniz Havzası, 2008'de keşfedilen petrol ve doğalgaz rezervlerinden itibaren stratejik olarak yeniden zirve haline gelmiştir (Aksoy, 2016, s. 1). Fakat bir başka açıdan Akdeniz, sanayileşme, hızlı kentleşme, deniz taşımacılığı, kontrolsüz büyüme gibi çevre için önem teşkil edecek tehditlerle karşı karşıya kalmaktadır. Çevresel tehditler kapsamına, havzada sanayi ve ticaretin yoğunluğu sebebiyle taşımacılık esnasında yaşanan petrol ve türevlerinin ekosisteme zarar vermesi örnek olarak verilebilmektedir (Paker, 2012, s. 157). Tablo 1'de, dünyada yaşanan bazı tanker kazaları sonucu denize dökülmüş petrol miktarları gösterilmektedir (Budak, t.y., s. 127-128). Bu kapsamda petrol taşımacılığının deniz kirliliğine verdiği belki de en önemli zararlardan birisi olarak, uluslararası çevreyi etkilemesi bakımından 1967'de gerçekleşen Torrey Canyon kazası gösterilmektedir. Kaza sonrasında uluslararası alanda petrol kirliliği ve deniz kirliliği gibi kavramlar dikkat çekmeye başlamıştır (Ünal, 2014, s. 9). Küresel ölçekli çevre sorunları, doğası gereği sınır ötesi sorunları da içerdiği için, bu sorunların çözümü için gerçekleştirilecek çabalarda; anlaşmalar, politikalar ve örgütlenmeler tam da bölgesel ölçekte işbirliğine dayalı anlaşmayı oluşturmaktadır (Paker, 2012, s. 157).

Tablo 1. Denizlerde Meydana Gelen Kaza Sonucu Denize Dökülen Petrol Oranları (CNN Türk Web Sitesi'nden aktaran Budak'ın çalışmasından (t.y., s. 127-128) faydalanılarak hazırlanmıştır)

\begin{tabular}{|c|c|c|c|}
\hline Y1l & Gemi ismi & Kaza yeri & Petrol Miktarı \\
\hline $\mathbf{1 9 9 1}$ & Gulfkriken & İran Körfezi & 910.000 \\
\hline $\mathbf{1 9 8 3}$ & Nowruz & İran Körfezi & 303.000 \\
\hline $\mathbf{1 9 8 3}$ & Castillo de Belver & Güney Afrika & 260.000 \\
\hline $\mathbf{1 9 7 8}$ & Amoco Cadiz & Fransa & 230.000 \\
\hline $\mathbf{1 9 8 0}$ & Irene's Serenade & Yunanistan & 102.000 \\
\hline $\mathbf{1 9 9 2}$ & Agean Sea & İspanya & 80.000 \\
\hline $\mathbf{1 9 9 4}$ & Nassia & İstanbul Boğazı & 20.000 \\
\hline
\end{tabular}

Akdeniz Havzası konusunda çevresel işbirliği önceliğinde bölgesel hedeflerin hayata geçirilmesi noktasında devletler, uluslararası kuruluşlar ve diğer paydaşlar birlikte hareket etmişlerdir. Bu zengin havzanın korunması için pek çok çalışmalar, işbirlikleri, entegrasyonlar yapılmıştır. Bunun bir örneği, Şubat 2016 yılında, Barselona Sözleşmesi çerçevesinde kabul edilen '2016-2025 Akdeniz Sürdürülebilir Kalkınma Stratejisi'dir (Birleşmiş Milletler Çevre 
Programı [UNEP], 2020). Benzer şekilde çevre sorunlarının neden olabileceği sosyo-ekonomik çalışmalar ile sürdürülebilirlik konusuna katkı sağlayan oluşumlardan biri de 'Akdeniz Sürdürülebilir Kalkınma Komisyonu (MCSD)' dur. Komisyon sivil toplum kuruluşlarını, hükümetleri ve yerel yetkilileri temsilen kırk paydaşı içermesi bakımından önemli bir konumdadır. Stratejik açıdan önemli olduğu düşünülen örneklerden biri de 'Barselona Sözleşmesi'dir. Resmi adıyla 'Akdeniz'in Kirliliğe Karşı Korunması Sözleşmesi', Akdeniz'e kıyısı olan ülkelerin taraf olduğu bir akittir (Birleşmiş Milletler Çevre Programı Akdeniz Eylem Planı [UNEPMAP], 2020).

Uluslararası alanda çevre sorunlarına çözüm bulmak amacıyla 5-16 Haziran 1972'de 'Birleşmiş Milletler Insan Çevresi Konferansi'nda (Stockholm Konferansı)' Birleşmiş Milletler Çevre Programı (UNEP) öncülüğünde Bölgesel Deniz Programları çalışmaları başlatılmıştır. Akdeniz'e kıyısı olan ülkeler ile Avrupa Ekonomik Topluluğu tarafından kabul edilerek uygulanmaya başlayan Akdeniz Eylem Planının (MAP) onaylanmasından sonra Şubat 1976'da bir araya gelen kıyı devletleri planın hukuki çerçevesini oluşturan Barselona Sözleşmesini kabul etmişlerdir. Türkiye'nin de akite taraf olduğu bu hukuki belgeler 1978' de yürürlüğe girmiştir (Algan, 2011, s. 38). Barselona sözleşmesinin adı 'Akdeniz Deniz Ortamı ve Kıyı Bölgesinin Korunması Sözleşmesi' olarak değiştirilmiş olup, 2002/4545 sayılı Bakanlar Kurulu Kararıyla; 22 Ağustos 2002 tarihinde 24854 sayılı Resmi Gazete'de yayımlanmıştır (Milletlerarası Andlaşma, 2020). Sözleşme kapsamında çalışmalar, 21 ülke ve Avrupa Birliği (AB) öncülügünnde yapılmaktadır. $\mathrm{Bu}$ ülkeler Harita 1'de görüldüğü üzere Arnavutluk, Cezayir, Bosna Hersek, Hirvatistan, Kıbrıs, Mısır, Fransa, Yunanistan, İsrail, İtalya, Lübnan, Libya, Malta, Monako, Karadağ, Fas, Slovenya, İspanya, Suriye, Tunus ve Türkiye' dir (UNEP, 2020).

Harita 1. Akdeniz Eylem Planı Koordinasyon Birimi Barselona Konvansiyonu ve Protokolleri (UNEP'in sitesinden faydalanılarak hazırlanmıştır)

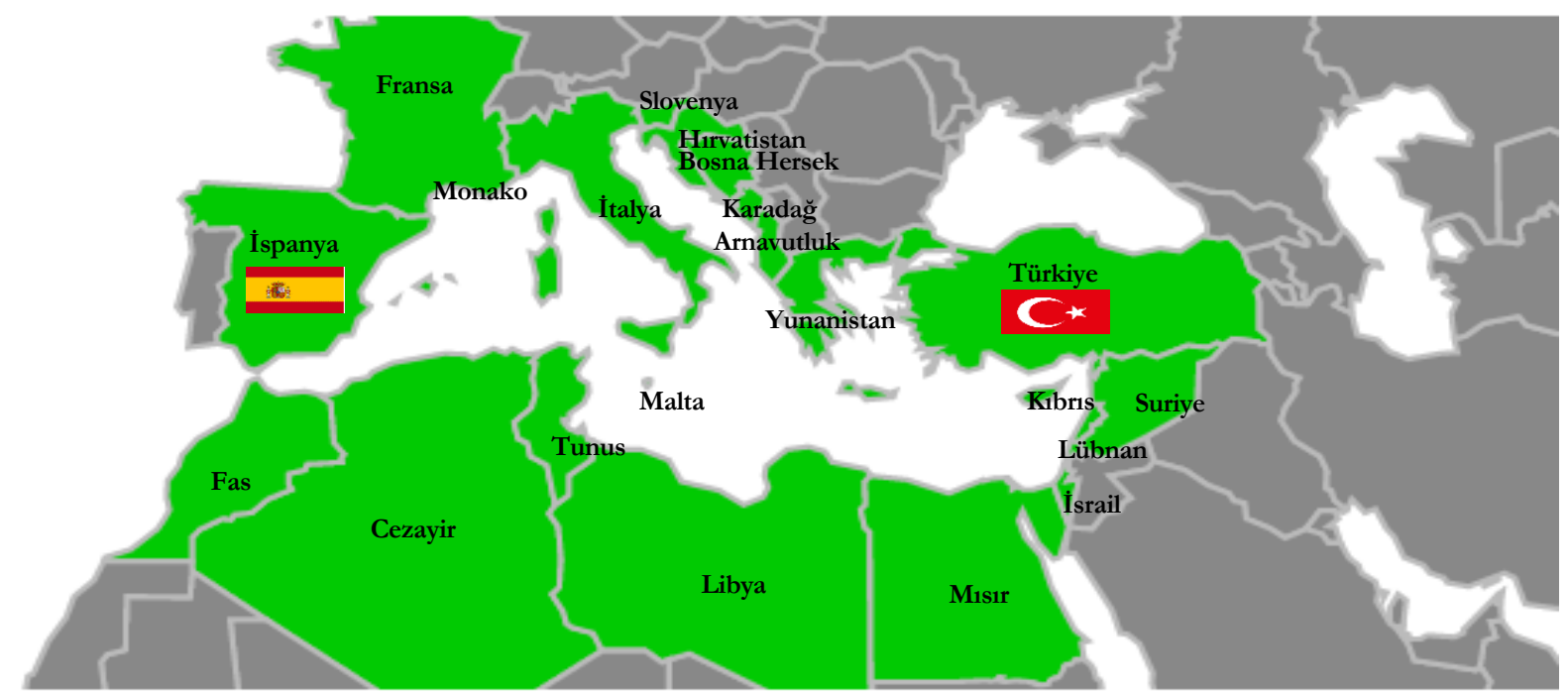

Akdeniz'de sürdürülebilir kalkınma hedefleri doğrultusunda çalışmalar genişleyerek yenilenmektedir (Arat, Türkeş ve Saner, 2002, s. 17). Bu noktada bir diğer önemli akit, deniz kirliliğini engellemek amaçlı oluşturulan 'Denizlerin Gemiler Tarafindan Kirletilmesinin Önlenmesine ait Uluslararası Sözleşme (MARPOL-73/78)' dir. Deniz çevresindeki önleyici tedbirler alınmasını sağlamış ve kirlilik konusunda dünya ölçeğinde kurallar getirilmesini sağlamıştır (Kara, 2004, s. 55-56 ve s. 160-161). Bu süreçte ülkeler, sivil inisiyatifler, uluslararası kuruluşlar etkili olmaktadır. Özellikle Greenpeace Akdeniz; havzadaki kirliliğe karşı Barselona 
Sözleşmesi'nin varlığının gerekliliğine dikkat çekmiştir. Bu ölçüde bölgesel alanda çalışmalar yapmıştır. Aynı zamanda havzadaki ülkeler, Barselona Sözleşmesi'ni onaylama sürecinde etkili olmuştur. Çevre Bakanlığı ile iletişim kurarak bilgi akışı, yoğun lobi çalışmaları ile bağlantıyı sağlamıştır (Paker, 2012, s. 168). Sözleşme kapsamında bulunan 7 protokol; Akdeniz Eylem Planı'nın yasal çerçevesini oluşturmakta ve havzanın farklı konularına çözüm bulmayı amaçlamaktadır (UNEP, 2020). Bu protokoller aşağıda belirtilmiştir:

- Akdeniz'de Gemilerden ve Uçaklardan Boşaltma veya Denizde Yakmadan Kaynaklanan Kirliliğin Önlenmesi ve Ortadan Kaldırılması Protokolü (Dumping Protocol)

- Akdeniz'in Kara Kökenli Kirletici Kaynaklara ve Faaliyetlere Karşı Korunması Protokolü (The Protocol on Land-Based Sources)

- Akdeniz'de Özel Koruma Alanları ve Biyolojik Çeşitliliğe İlişkin Protokol (Specially Protected Areas (SPA) Protocol)

- Olağanüstü Hallerde Akdeniz'in Petrol ve Diğer Zararlı Maddelerle Kirlenmesinde Yapılacak Mücadele ve İşbirliğine Ait Protokol (Prevention and Emergency Protocol)

- Akdeniz'in Tehlikeli Atıkların Sınırötesi Taşınması ve Bertaraf Edilmesinden Kaynaklanan Kirliliğe Karşı Korunması Protokolü (Hazardous Wastes Protocol)

- Açık Deniz Protokolü (Offshore Protocol)

- Entegre Kıyı Alanları Yönetimi Protokolü (Protocol on Integrated Coastal Zone Management (ICZM)

Akitin çalışma ve uygulamaları incelendiğinde; Akdeniz Havzasında meydana gelen ve taşıtlardan kaynaklanan kirliliğin önlenmesi, bölgede özel koruma alanlarının oluşturulması ve biyolojik çeşitliliğin sağlanması, Akdeniz'de bütünleşik kıyı alanları yönetiminin gerçekleştirilmesi ve Akdeniz'in ticari faaliyetlerden dolayı kirlenmeye karşı korunması gibi hususlar protokollerin temel amaçları olarak ortaya çıkmaktadır (Türkiye Cumhuriyeti Dişişleri Bakanlı̆̆1, 2020). Tablo 2'de görüldüğü üzere her protokolün kabulü ve yürürlüğe girişi farklı tarihlerde olmasına rağmen bazı protokoller yıllar içinde değişikliğe uğramıştır. Offshore Protokolü, Tehlikeli Atıklar Protokolü ve ICZM Protokolü'nde yürürlüğe giriş tarihinden sonra değişiklik yapılmamıştır. Damping Protokolü'nde ise yapılan değişiklik sonrasında protokolün henüz yürürlüğe girmediği Humphrey ve Lucas (2015, s. 9) çalışmasında ifade edilmiştir. 
Tablo 2. Barselona Sözleşmesi Kapsamında Yürürlüğe Giren Protokoller (Humphrey ve Lucas (2015, s. 9) çalışmasından ve UNEP sitesinden faydalanılarak hazırlanmıştır)

\begin{tabular}{|c|c|c|c|c|}
\hline Protokoller & Kabul Tarihi & $\begin{array}{l}\text { Yürürlüğe } \\
\text { Giriş Tarihi }\end{array}$ & $\begin{array}{l}\text { Değiştirilme } \\
\text { Tarihi }\end{array}$ & $\begin{array}{l}\text { Yürürrlüğge } \\
\text { Giriş Tarihi }\end{array}$ \\
\hline Damping Protokolü & 16 Şubat 1976 & 12 Şubat 1978 & $\begin{array}{l}10 \text { Haziran } \\
1995\end{array}$ & - \\
\hline $\begin{array}{c}\text { Önleme ve Acil Yardım } \\
\text { Protokolü }\end{array}$ & 16 Şubat 1976 & 11 Mart 1978 & 25 Ocak 2002 & 17 Mart 2004 \\
\hline LBS Protokolü & $\begin{array}{c}17 \text { May1s } \\
1980\end{array}$ & $\begin{array}{l}17 \text { Haziran } \\
1983\end{array}$ & 7 Mart 1996 & 18 Mayıs 2006 \\
\hline SPA Protokolü & 3 Nisan 1982 & 6 Kasım 1986 & $\begin{array}{l}10 \text { Haziran } \\
1995\end{array}$ & 12 Aralık 1999 \\
\hline Offshore Protokolü & 14 Ekim 1994 & 24 Mart 2011 & & \\
\hline Tehlikeli Atıklar Protokolü & 1 Ekim 1996 & 19 Ocak 2008 & & \\
\hline ICZM Protokolü & 21 Ocak 2008 & 24 Mart 2011 & & \\
\hline
\end{tabular}

Akdeniz ve kıyılarının korunması konusunda gelecek çalışmalara yön vermesi, havzanın korunmasına yönelik politikaların etkinliği, literatürde tamamlayıcı unsur olması, Barselona Sözleşmesi kapsamında yapılan bu çalışmayı önemli kılmaktadır. Literatür incelendiğinde, özellikle Türkçe literatürde bu konunun yeterince ele alınmadığının görülmesi de çalışmayı önemli kılan hususlardan bir diğeridir. İklim değişikliği sorunsalına koşut olarak, ülkelerin nasıl bir politika izlemesi gerektiğine ilişkin tespitlerin ortaya konulması bu çalışmanın konusunu oluşturmaktadır. Bölgesel ölçekte çevre konusunda yaşanan sorunların, Barselona Sözleşmesi'nin getirdiği çözüm önerilerinin etkinliği incelenmekte ve sözleşme hem Akdeniz Havzası özelinde hem de Türkiye özelinde ele alınmaktadır. Türkiye'nin tarafı olduğu diğer uluslararası sözleşmeler bağlamında ilişkisine bakılmakta, hangi ülkelerin çalışmalarının daha çok katkısı olduğu, özellikle hangi alanlarda etkili olduğu incelenmektedir. Fakat sözleşmenin alanı çok geniş olduğu için çalışma, akitin uygulama alanı 'Akdeniz'de Özel Koruma Alanları ve Biyolojik Çeşitliliğe İlişkin Protokolü' çerçevesinde İspanya ve Türkiye ülkeleri özelinde sınırlandırılmıştır. Çalışmada nitel yöntem kullanılmış, literatür taraması ağırlıklı olarak gerçekleştirilen çalışmada, uluslararası kurum ve kuruluşların analiz ve raporlarında da istifade edilmiştir. Elde edilen bulgular üzerinden yapılan analiz ve değerlendirmeler sonucunda uluslararası ölçekte yapılan önerilerle araştırma sonlandırılmıştır.

\section{Teorik Çerçeve ve Temel Kavramlar}

Bu bölümde, teorik bir çerçeve çizilmekte ve konunun daha iyi anlaşılabilmesi için bazı temel kavramlar detaylıca ele alınmaktadır. Bu bağlamda, uluslararası çözümler odağında akitin etkinliğini analiz edebilmek ve etkinliğini ortaya koyabilmek için çevre ve çevre kirliliği kavramları açıklanmakta, bu kavramlarla ilişkili olarak uluslararası ölçekte Barselona Sözleşmesi'nin tarihsel gelişimi anlatılmaktadır. Ayrıca, Akdeniz'in Kirliliğe Karşı Korunması 
Sözleşmesi'nin hangi konferans, toplantı ve sözleşmeler kapsamında revize edildiğine ilişkin süreç de incelenmektedir.

\section{1. Çevre ve Çevre Kirliliği}

Çevre kavramının kolay ölçüde anlaşılabilir bir tanımını yapmak çok da mümkün değildir. Anlama atfedilen yorumlara göre tanımlar değişmektedir. Bilhassa zengin anlam içeriği olan bir kavram olduğundan her alanda farklı tanımları yapılmaktadır (Gürkan, 2019, s. 526). Sadece Türk Dil Kurumu (TDK) tarafından sekiz farklı tanımı yapılmıştır. Bu tanımlardan toplum bilimi alanında en yaygın kullanılan tanımı: 'hayatın gelişmesinde etkili olan doğal, toplumsal, kültürel dış faktörlerin bütünlüğ̈̈̈' şeklindedir (Türk Dil Kurumu [TDK], 2020). Eski Türkçe etimolojisine baktığımızda çevre kelimesi 'çevür' eyleminden evrilmiştir (Etimoloji Türkçe, 2020). Çevre kavramının İngilizce etimolojisini incelediğimizde ise 'Environment' yani Fransizca 'environ' kelimesinden türemiştir (Etymology Dictionary, 2020).

1983 tarihli Çevre Kanunu'nda ise çevre, bireylerin yaşamlarını devam ettirdikleri ve zincir misali birbirleriyle etkileşim halinde oldukları fiziki, biyolojik, iktisadi ve sosyal ortam olarak tanımlanmaktadır (Çevre Kanunu, 2020). Diğer taraftan çevrenin çeşitli yazarlar tarafından farklı tanımlamaları da yapılmıştır. Örneğin, Kaypak (2012, s. 8) kavramı 'canlıların ortak yaşama alanlarını oluşturan hava, su ve toprak' şeklinde ifade etmektedir. Hilal ve Doğan'a (2018, s. 99) göre canlıların yaşadığı ve önemli faaliyetlerini devam ettirdiği habitattır. Büyükgüngör (2006, s. 1) ise çevreyi 'canlıların yaşamı boyunca ilişkilerini sürdürdüğü dış ortam' olarak açıklamaktadır. Çevre 'çeşitli ölçeklerde ve miktarlarda bir kaynaklar bütünü' olarak ifade edilmektedir (Baykal ve Baykal, 2018, s. 12). Kelimenin geniş bir anlamı olduğu için hayat boyu organizmaları etkileyen her şeyi ele aldığından aslında bir nevi yalnızca kişinin çevresi olarak da gösterilmektedir (Chauhan, 2008, s. 6). Çevre kelimesi konuya, gündeme, bakış açısına göre ortaya çıkıp değiştiklerinde ve tartışıldıklarında gündemin dinamiklerini göstermektedir (Myerson ve Rydin, 1996, s. 6).

Bu kapsamda çevre kirliliğinin de birçok tanımı bulunmaktadır. TDK'nin yaptığı çevre kirliliği tanımı 'doğal kaynakların aşırı ve yanlış kullanılması, tahrip edilmesi sonucunda çevrede dengenin olumsuz yönde bozulması ve birtakım sorunların ortaya çıkması' şeklindedir (TDK, 2020). Çevre Kanununda ise çevre kapsamında 'canlıların să̆hl̆ğmı, çevresel değgerleri ve ekolojik dengeyi bozabilecek her türlü olumsuz etki' olarak açıklanmaktadır (Çevre Kanunu, 2020). Kaypak (2012, s. 209) ise çevre kirliliğini, tabiatın kendini arındırma yetisinin üstünde olan işlerin çevrede oluşturduğu yığılımlar olarak ifade etmektedir. Çevre kirliliği, sanayi atıkları, kontrolsüz kentleşme ve atıkların tabiata atılması şekilde oluşmaktadır (Güven vd., 2005, s. 3). Kirlilik, olağanüstü hızla yayılmaktadır (Dobson, 2016, s. 19).

Kuşkusuz, çevre sorunları yirmi birinci yüzyılın en mühim sorunlarından biridir. Küresel ölçeğe ulaşmış bu sorunlara yine bu ölçekte yer alan paydaşlarca tepkiler verilmektedir (Tuna, 2011, s. 8). Uluslararası ölçekte baktığımızda kirlilikle mücadele, en önemli uğraş alanlarından biridir (Baykal ve Baykal, 2008, s. 4). Çevre kirliliğinin sınır tanımaması bunun yanı sıra çevre kavramının tüm insanlık için ortak bir miras olarak algılanması, çevre sorunlarına küresel bir boyut getirmiştir (Kılıç, 2001, s. 135). Örneğin uluslararası alanlardaki boyutlarına bakıldığında 1970'lerden itibaren 'iklim değişikliği, küresel ısınma, ozon tabakasının ve ormanların tahribatı' meseleleri ile karşılaşılmaktadır (Gürkan, 2019, s. 534). Gelinen bu nokta, doğa için tehlikeli durum oluşturmaktadır (Abdulhakimoğulları, Sezer ve Akpınar, 2011, s. 63). Bu sorunların 
aşılabilmesinin bir gereği olarak da, küresel ölçekte sorunlar, uluslararası platformda çözüm öneren sözleşmelerin doğmasına sebep olmuştur (Kılıç, 2001, s. 135).

Akdeniz, Avrupa Birliği'nin yanı sıra birçok kıyı ülkesini de kapsayan yarı kapalı bir denizdir. Havzayı oluşturan ülkeler; Arnavutluk, Bosna Hersek, Cezayir, Fas, Filistin, Fransa, İspanya, İsrail, İtalya, Kıbrıs Rum Kesimi, Kuzey Kıbrıs Türk Cumhuriyeti, Libya, Lübnan, Malta, Mısır, Slovenya, Suriye, Tunus, Türkiye ve Yunanistan'dır. Özellikle son dönemde havza; enerji, ticaret, ekonomi ve çevre gibi birçok alanda karşılıklı etkileşimin yaşandığı bir bölge olmuştur (Yıldız, 2016, s. 616-617). Kara kökenli kirlilikler, uluslararası deniz ticaret hacmi kirliliği, fırsatçı istilacı türlerin gelmesi ve petrol taşımacılığın yol açtığı kirlilik türleri pek çok deniz canlısını etkilemekte ve bölgenin ekosistemi üzerinde baskılara neden olmaktadır (UNEP, 2020). Geçmişte, Akdeniz'e kıyısı olan ülkelerde yaşanan su kıtlı̆ğ yüzünden pis su kaynaklı atık su kullanımı etkinlik sağlayamamış, gün geçtikçe bu sorun, Akdeniz Havzasında yaşanan kirliliğe karşı bir farkındalık algısı oluşmasını sağlamıştır (Özoğuz, 2005, s. 3-4).

Küresel ticaretin gelişmesine koşut olarak, günümüzde, gemi ve tankerlerden kaynaklanan petrol ve türevlerinin kirliliği de önemli boyutlara ulaşmıştır (Abdullahzade, 2009, s. 696-697). Örneğin 19 Mart 1994'te Sarıyer-Beykoz açıklarında Güney Kıbrıs bayraklı yük gemisi ve Rum bayraklı petrol tankerinin çarpışması sonucu iki geminin yanması esnasında oluşan petrol atıkları sebebiyle havzada geniş çapta çevre kirliliği meydana gelmiştir (Kara, 2004, s. 127). Petrol taşımacılığının \%20'si Akdeniz Havzası aracılığıyla yapılmakta olduğundan bölgede 82 merkez petrol limanı ve rafinerisi bulunmaktadır. Havzada günlük işlenmiş varil miktarı ise 8.780.326'dır. UNEP MAP verilerine bakıldığında Akdeniz'de her yıl 100-150.000 ton petrolün taşıma esnasında denize döküldügü görülmektedir. 1985-2007 yılları arası incelendiğinde ise havzada 27 büyük kaza olduğunda bahsedilmektedir (Legambiente and the Civil Protection Department, 2007). Yarı kapalı bir deniz olan Akdeniz; sahip olduğu ticaret hacmi, enerji ve deniz ulaşımında düğüm noktası olması nedeniyle, geçmişte de bugün de, petrol kirliliğine maruz kalması anlamında tehlikeli durumlarla karşı karşıya kalmış ve halen de kalmaktadır. Bu sebeple Türkiye de bu havzanın önemli bir paydaşı olarak bu sorunla çok daha dikkatli şekilde ilgilenmek zorunda kalmıştır (Abdullahzade, 2009, s. 697- 698).

Çevre kirliliğini mümkün olabildiğince kaynağında ve oluşmadan önlemek, mümkün olamıyorsa en aza indirgemek için gerekli politikaları üretmek, ekolojik dengeyi sürdürülebilir kılmanın belki de en önemli yaklaşımlarından biridir. Bu bağlamda, farklı ölçeklerde ve farklı boyutlarda çözüm önerilerinin geliştirilmesi kaçınılmazdır. Baykal ve Baykal (2008, s. 14) çalışmasında bu hususla ilgi olarak; atık miktarlarının düşük seviyelerde tutulabileceğini, çevre kirliliğinin önlenmesinde teknolojik önlemler alınıp uygulanabileceğini ve başka bir yol olarak gerçekçi boyutunu da ele alan çevresel bağlamı odak alan bir planlama düzenlenebileceğine vurgu yapar. İşte bu bağlamda, Akdeniz Havzası özelinde çevre kirliliğini önlemek, deniz kirliliğini azaltıp denetlemek amacıyla bölgesel ölçekte işbirliği planlaması yoluna gidilmiş ve Akdeniz'e kıyısı olan devletlerin taraf olduğu Barselona Sözleşmesi imzalanarak yürürlüğe girmiştir (T.C. Çevre ve Şehircilik Bakanlığı, 2016, s. 95).

\subsection{Uluslararası Çözümler Bağlamında Barselona Sözleşmesi}

Çevre konusunun uluslararası bir gündem haline gelmesinde 1972'de İsveç'in Stockholm şehrinde gerçekleştirilen ve ilk çevre zirvesi olan 'Birleşmiş Milletler İnsan Çevresi Konferansı' toplantısı etkili olmuştur (Arat, Türkeş ve Saner, 2002, s. 7). Konferansta çevre ölçeğinin küresel bir problem olduğundan bahsedilmiş, tüm devletlerin birlikte tedbir alması gerektiği 
düşünülmüş, hatta bu kapsamda uluslararası antlaşmalar yöntemine gidilmiştir (Taze ve Güneş, 2012, s. 76). Toplantıda alınan kararlar kapsamında 'Birleşmiş Milletler Genel Kurulunun 15 Aralık 1972 tarihli 2997 sayılı kararıyla Birleşmiş Milletler Çevre Programı (UNEP)' örgütü kurulmuştur (T.C. Dişişleri Başkanlığı, 2020). UNEP kılavuzluğunda Bölgesel Deniz Programı çalışmalarına başlanmış (Güneş, 2001, s. 56) ve bu kapsamda Akdeniz Havzasının korunması, önde gelen hedeflerden biri olmuştur. Bu doğrultuda 1974'te 'Bölgesel Denizler Programı Faaliyet Merkezi' oluşturularak 'Akdeniz Eylem Planı (AEP)' hazırlanması sağlanmıştır (Arat, Türkeş ve Saner, 2002, s. 14).

AEP 1975'te Akdeniz Havzasındaki ülkeler ile AET tarafından onaylanarak uygulamaya geçilmiştir. Kabulünden sonra planın hukuki çerçevesini meydana getiren 'Akdeniz'in Kirlenmeye Karşı Korunması Sözleşmesi (Barselona Sözleşmesi)' 16 Şubat 1976'da imzalanmış ve 1978'de yürürlüğe girmiştir (Algan, 2011, s. 38). Sözleşme, UNEP Bölgesel Deniz Programları'nın da en önemli örneğini meydana getirmiştir (Güneş, 2001, s. 75). Türkiye sözleşmeye 1982 yılında taraf olmuş ve 2014-2015 yıllarında dönem başkanlığını yerine getirmiştir (T.C. Çevre ve Şehircilik Bakanlığı, 2020).

Şekil 1. Barselona Sözleşmesi'nin Tarihsel Gelişimi (UNEP'in ve T.C. Çevre ve Şehircilik Bakanlığı'nın sitelerinden faydalanılarak hazırlanmıştır)

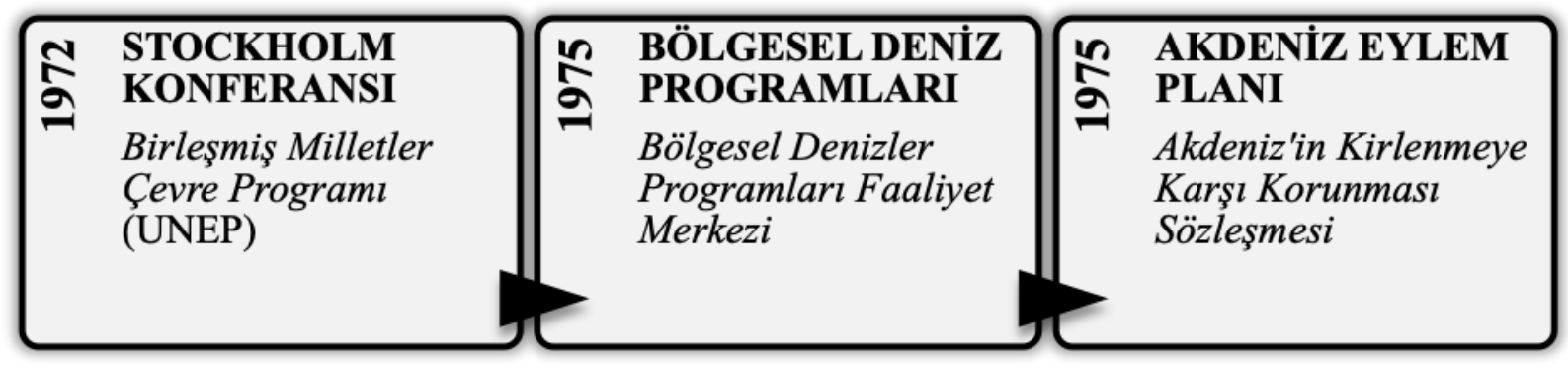

Çevre alanında küresel ölçekte önemli diğer bir konferans ise 3-14 Haziran 1992' de Rio şehrinde düzenlenen 'Çevre ve Kalkınma Konferansı' dır. Toplantıda beş temel belge ele alınmıştır. Bunlar: 'Rio Deklarasyonu, Gündem 21, Orman Prensipleri, İklim Değişikliği Sözleşmesi ve Biyolojik Çeşitlilik Sözleşmesi' belgeleridir (Arat, Türkeş ve Saner, 2002, s. 6). Zirvede ayrıca AEP ve Barselona Sözleşmesi belgelerinde de yenilik yapma isteği duyulmuştur. Bu bağlamda Barselona'da bir araya gelen sözleşme tarafları yeni belgeleri kabul etmiştir (T.C. Çevre ve Şehircilik Bakanlığı, 2020). AEP'nin 1995'te genişletilmiş yeni hali (MAP II), Barselona Sözleşmesi'nin yapılandırılmasıyla desteklenmiştir (Paker, 2012, s. 162). AEP yalnızca denizlerin korunması konulu bir belge olmaktan ziyade Akdeniz Havzası'nda sürdürülebilir kalkınmayı amaçlamıştır (Arat, Türkeş ve Saner, 2002, s. 6). Diğer yandan, Akdeniz özelinde düşünüldüğünde Barselona Sözleşmesi ise Akdeniz Havzası'nın korunması için çok düzlemli ve kapsamlı yasal bir çerçeve oluşturmuştur.

Barselona Sözleşmesi ve bünyesinde bulunan protokoller çevre alanında farklı konulara değinmektedir. Her protokolün paydaşları bundan dolayı farklıdır. Türkiye bütün protokollere taraf ülke konumunda değildir (UNEP, 2020). Sözleşme protokolleri, Akdeniz'deki kirliliği önlemek, havzayı kontrol etmek ve korumak için bir çerçeve 
sunmaktadır (U.S. Department of The Interior, The Office of Water Research and Technology, 1978, s. 78).

- Damping Protokolü, Akdeniz Havzası'ndaki gemilerin ve uçakların sebep olduğu kirliliği yok etmek ve azaltmak için ihtiyaç duyulan tüm tedbirlerin alınması gayesiyle imzalanmıştır (Convention for the Protection of the Mediterranean Sea against Pollution, t.y., s. 3-4). Akit taraflarları bazı hususlarda fikir birliğine varmıştır. Örneğin atıkların atılması ya da yakılmasıyla deniz kirliliğinde oluşan tehlikenin farkındalığı boyutunda anlaşmışlardır (Protocol for the Prevention and Elimination of Pollution of the Mediterranean Sea, t.y., s. 23).

- LBS Protokolü, akarsuların, kıyı yerleşimlerin ve kara kökenli kaynakların neden olduğu Akdeniz'deki kirliliği hafifletmek için önlemler noktasında çalışmaktadır (Convention for the Protection of the Mediterranean Sea against Pollution, 2020, s. 4). Akdeniz Havzası'ndaki sanayileşme ve şehirleşmeye paralel olarak artan nüfus çerçevesinde kara kökenli kaynakların sebep olduğu zararları engellemek amacıyla hazırlanmıştır (Arat, Türkeş ve Saner, 2002, s. 18). Türü açısından gözlemlendiğinde en mühim protokoldür. Protokol sorumluluk ve işbirliği konusunda bir çerçeve sunmaktadır. Örneğin kanalizasyon meselesinde bölgeye özgü atık su kullanımını incelemektedir (UNEP, 2020).

- SPA Protokolï, Akdeniz Havzası'ndaki özel koruma alanları ve biyoçeşitlilik konularıla ilgilenmektedir (UNEP, 2020). Akdeniz'deki doğal sit alanlarının, tabiat varlıklarının ve kültürel değerlerin, çevre ve deniz alanlarının korunması gayesiyle imzalanmıştır (Arat, Türkeş ve Saner, 2002, s. 19). SPA Protokolü, 'kıyı ve deniz biyoçeşitliliğin yerinde sürdürülebilir yönetimi' ile ilişkili 1992 Biyolojik Çeşitlilik Sözleşmesi'ni yerine getirmek için Akdeniz' in ana vasıtasıdır (Regional Activity Centre for Specially Protected Areas [RAC/SPA], 2020).

- Önleme ve Acil Yardım Protokolü, olağanüstü durumlarda petrol ve türevlerinin neden olduğu kirlilikle mücadele noktasında çalışmaktadır (UNEP, 2020). Denizlerde yaşanılan kaza sonrasında paydaşlar arasındaki entegrasyonlar vasıtasıyla alınacak gerekli tedbirlerin neler olduğu noktasında incelemeler yapmaktadır (Arat, Türkeş ve Saner, 2002, s. 19).

- Tehlikeli Atıklar Protokolü'nün çalışma alanı Akdeniz Havzası'ndaki zararlı atıkların sınırdışına gitmesi ve bertaraf edilmesidir (UNEP, 2020). Tehlikeli atıklar protokolünün konferansı 1996 yılında İzmir'de yapılmıştır (Birleşmiş Milletler Çok Taraflı Çevre Anlaşmaları Bilgi Portalı [InforMEA], 2011).

- Açık Deniz Protokolü' nün çalışma kapsamı Akdeniz Havzası'nın kıta sahanlığı ve topraklarının keşfinin neden olduğu kirliliğe karşı muhafaza edilmesi noktasıdır (UNEP, 2020). Bu protokol ötekilerinin yanı sıra 'izin gerekliliklerini, terk edilmiş veya kullanılmayan tesislerin kaldırılmasını, zararlı maddelerin uzaklaştırılmasını, sorumluluk ve tazminat yükümlülüklerini' ve Barselona Sözleşmesi'nin başka yerlerle bağlantısını sağlamaktadır (Avrupa Yasal Veri Portalı [EUR-Lex], 2014). Türkiye bu protokole taraf değildir (UNEP, 2020).

- ICZM Protokolü, bütünleşik kıyı alanları yönetimi konularıyla ilgilenmektedir (UNEP, 2020). Kıyı kesiminin önemi sözleşmeye taraf ülkelerin politik odağında olacağından 
bu protokol önemli noktadadır (Öncelikli Eylemler Programı/ Bölgesel Faaliyet Merkezi [PAP/RAC], 2020). Türkiye bu protokole taraf değildir (UNEP, 2020).

Görüldügü gibi tüm bu protokoller havzanın barındırdığı sorunlar ve bu sorunların büyüme kapasitesine göre farklı fakat birbirleriyle ilişkili olabilecek alanlarda hazırlanarak ele alınmıştır. Paker (2012: s. 167)'de bu konunun altını çizerek, protokollerin her birinin, Akdeniz'deki farklı meselelere çözüm bulmayı amaçladığını vurgular.

\section{Barselona Sözleşmesinin Uygulama Performansının İspanya Özelinde Değerlendirilmesi}

Akdeniz'in korunması bütüncül bir bakış açısıyla küresel ölçekte çevrenin korunmasına bağlıdır. Diğer taraftan, gerek küresel ölçekte olsun gerekse ulusal ve ulusaltı ölçeklerde olsun, çevrenin korunması ve imzalanan çevre sözleşmelerinin uygulanmasındaki esas görev ise ulusal ölçekte devletindir. Bu sistemin işleyebilmesi, güçlü bir iradenin oluşuna ve bu iradenin süreci etkin bir şekilde yürütmesine bağlıdır (Kaya, 2011, s. 457). Örneğin İspanya'ya bakıldığında; çevrenin, bölgenin ve habitatın korunması süreci için bölgesel ve ulusal nitelikte mevzuatını düzenlediği ve bu bağlamda hukuki bir altyapı hazırladığı görülür. Bu bağlamda, Akdeniz Havzası'ndaki ülkeler, yeni koruma bölgeleriyle ilgili pek çok teklifin ve tehlike altındaki türlere ait çizelgelerin gösterildiği Barselona Sözleşmesi aracılığıyla paydaş bir yasal sınıra sahip olmuşlardır (López Ornat, 2014, s. 25-26).

Barselona Sözleşmesi'nin uygulama performansının ortaya konulması açısından çalışma, 'Akdeniz'de Özel Koruma Alanları ve Biyolojik Çeşitliliğe İlişkin (SPA/BD) Protokolü' ile sınırlandırılmıştır. Bu açıdan ele alındığında SPA Protokolü için López Ornat (2014, s. 50), özellikle kıyı kesimi ve deniz bağlamında Akdeniz Havzasını korumak için en önemli sınır ötesi araç olduğuna vurgu yapar. Şekil 2'de de görüleceği üzere; Cenevre şehrinde 1982'de kabul edilen 'Akdeniz'de Özel Koruma Alanlar Protokolü (AÖKA)'nün yerini 1995'te Barselona'da imzalanan 'SPA/BD Protokolü (Specially Protected Areas and Biological Diversity)' almıştır. Yürürlüğe 1999 'da giren bu protokol, canlı çeşitliliğini muhafaza etmeyi ve doğal yapının kültürünü korunmayı amaçlamıştır (RAC/SPA, 2020). AÖKA 2001'de kamuya duyurulmuş olup 2003'te de on dört AÖKA açıkça bildirilmiştir. Bu protokol kapsaminda '140'tan fazla deniz ve kıyı koruma alanı' on dokuz Akdeniz Havzası ülkesi tarafından tanınmıştır (López Ornat, 2014, s. 23-50).

Şekil 2. SPA/BD Protokolü Tarihsel Süreci (RAC/SPA'nın sitesinden ve López Ornat (2014, s. 23) çalışmasından faydalanılarak hazırlanmıştır)

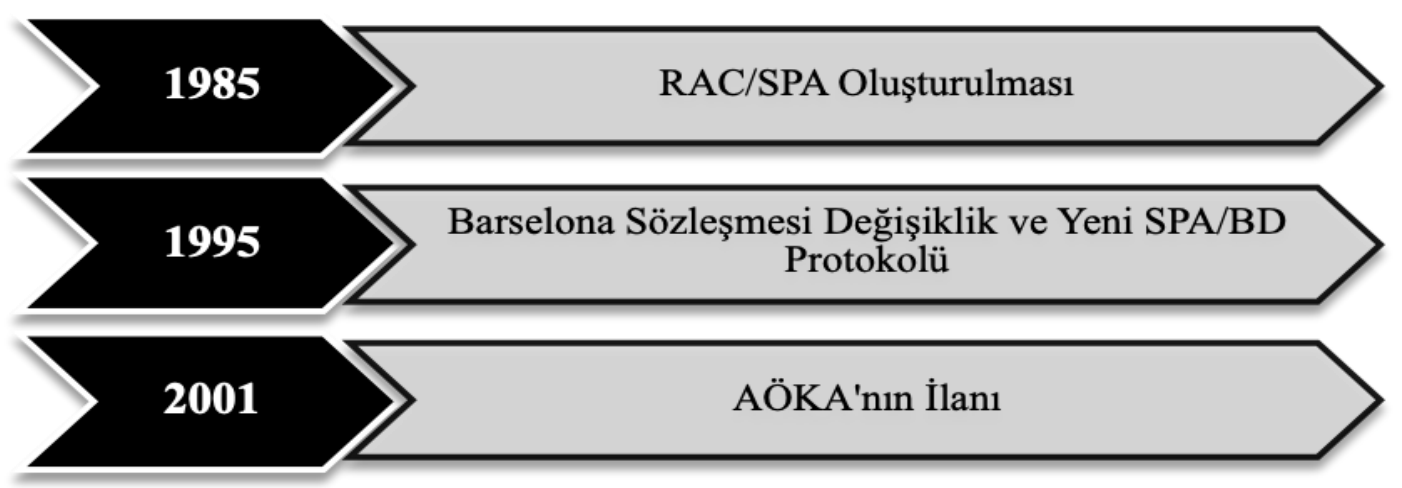

Barselona Sözleşmesi'nin Bölgesel Aktivite Merkezleri'ne bakıldığında 'Özel Koruma Alanları Bölgesel Faaliyet Merkezi (RAC/SPA)'nin genel merkezi Tunus'ta bulunmaktadır (T.C. Çevre ve 
Şehircilik Bakanlığı, 2020). Tunus' ta SPA protokolü toplantısında yeni bir araç olarak 'Akdeniz Açısından Önemli Olan Özel Koruma Alanları (AÖKA)' açıklanmıştır. SPA/BD Prokolü' ne ait ek, Monako şehrinde 24 Kasım 1996' da tasdik edilmiştir. Aynı zamanda Ek II ve Ek III kararları sirasiyla 30 Mart 2014 ve 16 Nisan 2015 tarihlerinde uygulamaya konulmuştur (UNEP, 2017). Protokolün ekleri ölçeğinde farklı konular incelenmiştir. Örneğin Ek 2'de 15 tür kuş çeşidinin korunması için eylem planı hazırlanmıştır (RAC/SPA, 2011).

İspanya özelinde incelendiğinde, hükümet, Barselona Sözleşmesi SPA Protokolünü 3 Nisan 1982' de imzalamış, 22 Aralık 1987' de onaylanmıştır. SPA/BD Protokolü ise 10 Haziran 1995'te imzalanmış ve 23 Aralık 1998' de onaylanmıştır (RAC/SPA, 2010). Harita 2'de görüldügü üzere sözleşmenin Bölgesel Aktivite Merkezlerine bakıldığında Temiz Üretim Bölgesel Aktivite Merkezi (CP/RAC), İspanya'da bulunmaktadır. Diğer bölgesel merkezler ise Yunanistan, Hırvatistan, Fransa, İtalya, Tunus ve Malta ülkeleridir (T.C. Çevre ve Şehircilik Bakanlığı, 2020).

Harita 2. Barselona Sözleşmesi Sekretarya ve Bölgesel Aktivite Merkezleri (T.C. Çevre ve Şehircilik Bakanlığ1, t.y.)

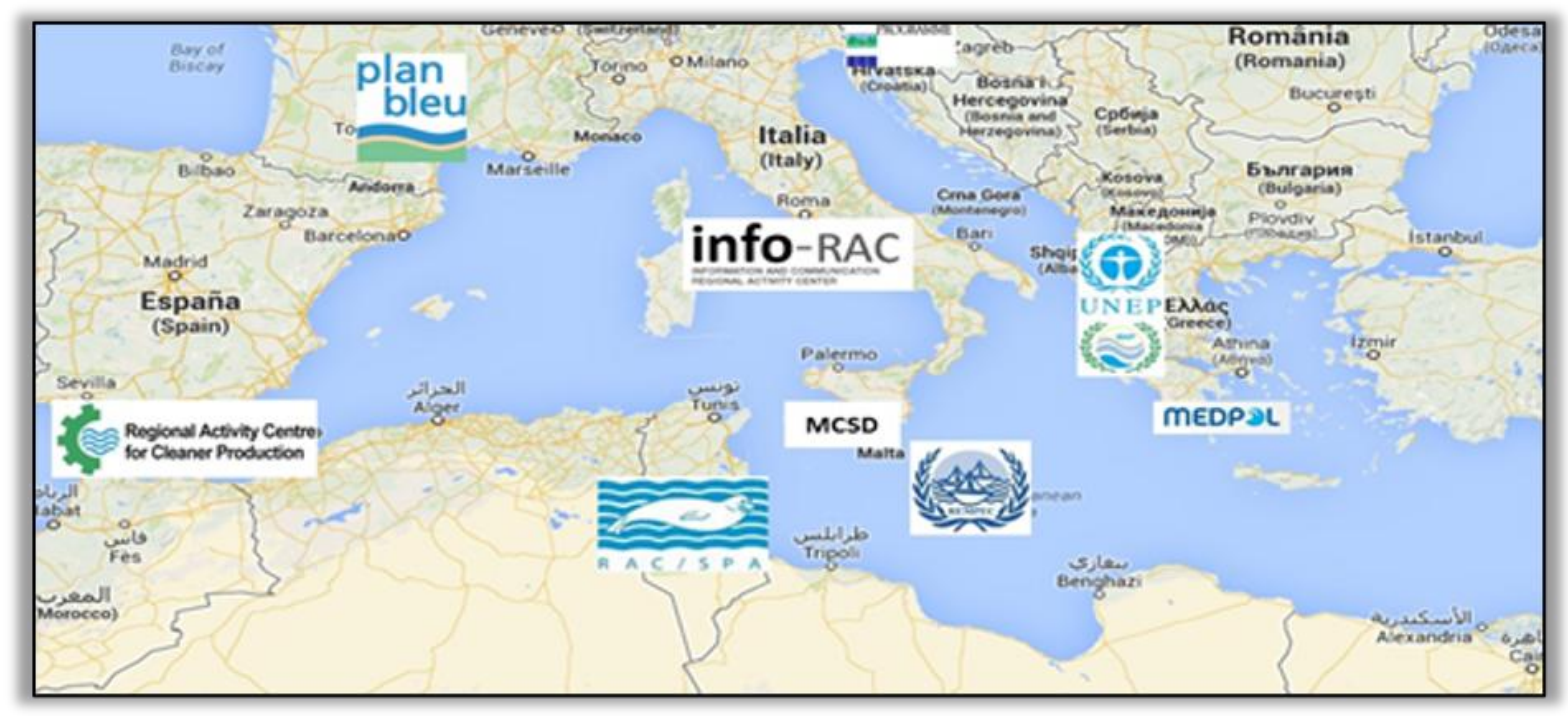

Her ülkede farklı koruma alanları türleri vardır. 'Deniz Koruma Alanları' nın (DKA)' gayesi mühim olan doğal türlerin muhafaza edilmesidir. 'Akdeniz Özel Koruma Alanları (SPAMIs)' ise deniz ve kıyı canlı hayatlarını korumaktadır (RAC/SPA, 2020). Harita 3'te Kasım 2017'de güncellenmiş SPAMI listesine bakıldığında 35 alan görülmektedir (UNEP, 2017). Listede Arnavutluk, Cezayir, Kıbrıs, Fransa, İtalya, Lübnan, Fas, Tunus ve İspanya ülkelerinin koruma alanları bulunmaktadır (RAC/SPA, 2020). 
Harita 3. Akdeniz Özel Koruma Alanları (SPAMI) Listesi (UNEP)

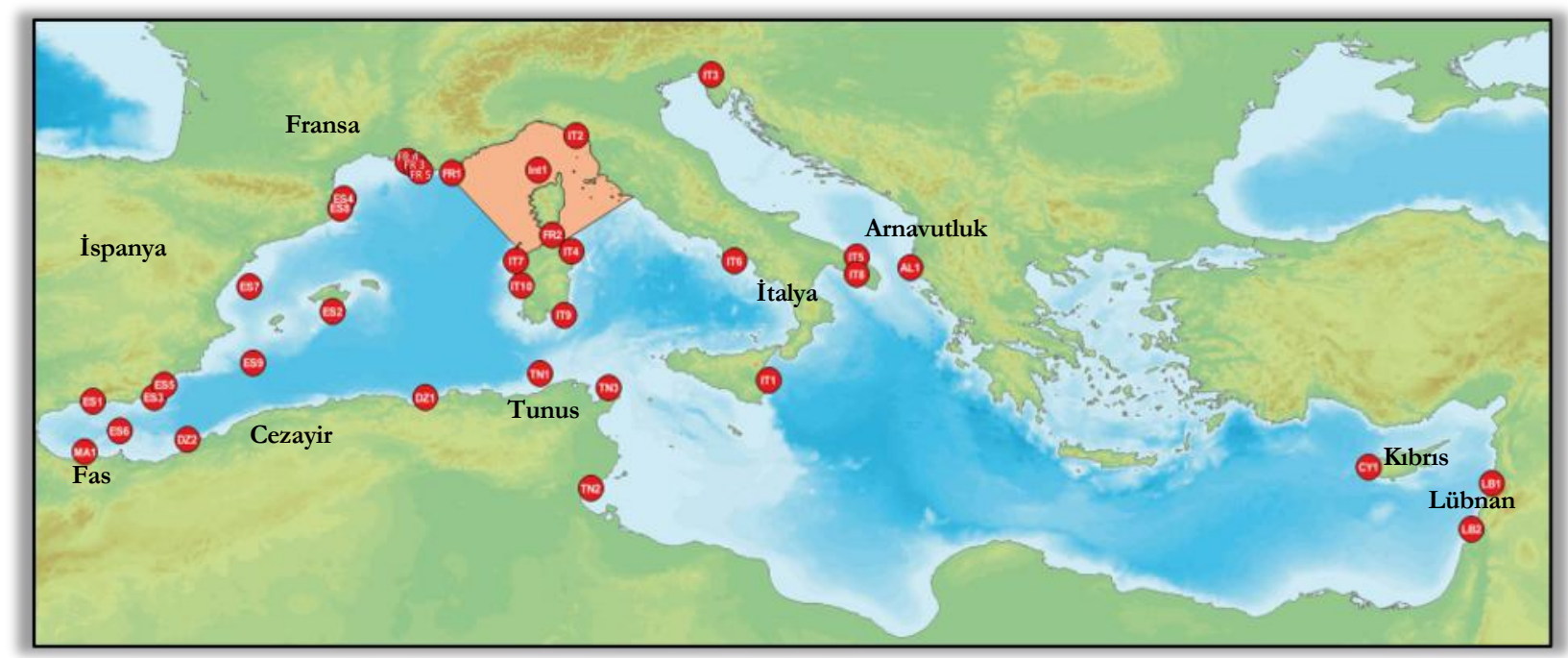

Tablo 3'te görüldüğü üzere İspanya özelinde sekiz adet koruma alanı bulunmaktadır ve bu koruma alanları 2001 yılından itibaren belirlenerek yürürlüğe girmişlerdir.

Tablo 3. İspanya'da Bulunan Özel Koruma Alanları (SPAMI) Listesi (RAC/SPA'in sitesinden faydalanılarak hazırlanmıştır)

\begin{tabular}{|c|c|}
\hline Koruma Alanı & Yı1 \\
\hline Maro-Cerro Gordo Kayalıkları (ES1) & 2003 \\
\hline Cabrera Takımadaları Milli Parkı (ES2) & 2003 \\
\hline Cabo De Gata-Nijar Doğal Parkı (ES3) & 2001 \\
\hline Cap De Creus Doğal Parkı (ES4) & 2001 \\
\hline Almeria Levante Denizaltı (ES5) & 2001 \\
\hline Alboran Adası (ES6) & 2001 \\
\hline Columbretes Adaları (ES7) & 2001 \\
\hline Medes Adaları (ES8) & 2001 \\
\hline
\end{tabular}

Koruma alanları akit taraflarının belli bir ölçü doğrultusunda verdikleri karara göre listeye dahil olmaktadır (RAC/SPA, 2020). İspanya'ya baktığımızda birçok Milli Parkı, Habitat Parkı, Tabiat Anıtı ve deniz rezervi bulunmaktadır. Örneğin İspanya'da bulunan Cabo De Gata-Nijar Doğal Parkı biyosfer rezervdir. (Ornat, 2014, s. 24-50). Valencia şehrinde bulunan 1,754 hektarlık alana sahip Tabarca Adası, deniz rezervlerine örnektir. İspanya hükümeti Tarım, Balıkçılık ve Gıda Bakanlığı faaliyet alanlarını güncel olarak yenileyip halka sunmaktadır (İspanya Hükümeti Tarım, Balıkçılık ve Gıda Bakanlığı, 2020). 


\section{Barselona Sözleşmesi'nin Uygulama Performansının Türkiye Özelinde Değerlendirilmesi}

Dünya ülkeleri, çevrenin korunması ve küresel ekosistemin sürdürülebilirliğinin sağlanması konusunda hemen hemen her ölçekte, çok çeşitli inisiyatifler oluşturmuşlar ve bu konudaki kararlılıklarını da göstermişlerdir. Türkiye de bu inisiyatifin önemli bir parçası olarak; çevreyi, biyoçeşitliliği ve habitatı korumak gayesiyle sorumluluk almış ve bu sorumluluklarını da uluslararası anlamda en iyi şekilde devam ettiren ülkelerden biridir. Öyle ki, Taze ve Güneş (2012: s. 76)' in de söylediği gibi, Türkiye bu bağlamda hazırlanan pek çok antlaşmada taraf ülke konumundadır. Bu bağlamda, Türkiye'nin korunması gerekli olan alanlar ölçeğinde taraf olduğu uluslararası sözleşmeler aşağıda belirtilmiştir (Güler ve Çobanoğlu, 2001, s. 26-27):

- 'Avrupa'nın Yaban Hayatı ve Yaşama Ortamlarmı Koruma Sözleşmesi (Bern Sözleşmesi)' ölçeğinde korunmaya alınan bölgeler

- 'Akdeniz'in Kirlenmeye Karşı Korunması Sözleşmesi (Barselona Sözleşmesi)' kapsamında belirlenen korunma bölgesi alanları

- 'Dünya Kültür ve Tabiat Mirasının Korunması Sözleşmesi'nin gereğince Kültür Bakanlı̆̆ı tarafından koruma altına alınan Kültürel Miras ve Doğal Miras statüsü verilen alanlar' (Güler ve Çobanoğlu, 2001, s. 26-27).

Barselona Sözleşmesi'nin odak noktasında yer alan bir ülke olarak Türkiye, denizlerde oluşan kirliliğin önlenmesine yönelik olarak uyguladığı yöntem ve politikalara bağlı olarak, ölçüm ve analizler yapmakta ve bu veriler her iki yılda bir Barselona Sözleşmesi Sekretaryasına gönderilerek raporlanmaktadır (T.C. Çevre ve Şehircilik Bakanlığı, 2020). Çevre kirliliği konusu, bilhassa deniz kirliliği, Türkiye için stratejik önemi haiz bir konuda bulunduğundan, Kara (2004: s. 85-86)'nın da vurguladığı gibi, alınacak önlemlerin bütünsel bir yaklaşım içinde ele alınması ve uygulanması gerekmektedir.

Yukarıda, bu çalışmanın, SPA/BD Protokolü çerçevesinde sınırlandırılmış olduğu söylenmişti. Bu bağlamda Özel Koruma Alanları Protokolü (SPA) 1982'de kabul edilmiş, Türkiye'de 6 Kasım 1986'da yürürlüğe girmiştir. Sonrasında adı revize edilen Özel Koruma Alanları ve Biyoçeşitlilik Protokolü (SPA/BD) 1995'te onaylanmış, Türkiye'de ise 18 Eylül 2002'de tasdik edilmiştir (UNEP/MAP, 2013, s. 25). Türkiye, biyoçeşitlilik açısından ele alındığında Akdeniz Havzası'ndaki en verimli mıntıkalardan biridir. Akdeniz' in Türkiye sınırlarında 388 çeşit balık yer almaktadır (T.C. Çevre ve Şehircilik Bakanlığı, 2016, s. 192). Biyoçeşitliliği muhafaza etmek için birbirinin eksikliklerini gideren 'ex-citu (doğal yaşam alanı dışında koruma ya da yapay koruma) ve in-suti (doğal yaşam alanında koruma ya da yerinde koruma) yaklaşımları' benimsenmektedir (T.C. Çevre ve Şehircilik Bakanlığı, 2016, s. 203).

Özel Koruma Alanları, tarihi, sosyal ve doğaya ait olan gerek bölgesel gerek küresel bazda ekolojik değeri yüksek olan bölgelerdir (Atmaca ve diğerleri, 2006, s. 25). UNEP'in Akdeniz Özel Koruma Bölgeleri listesine bakıldığında Türkiye'nin koruma alanı bulunmamaktadır (UNEP, 2020). Çevre ve Şehircilik Bakanlığı'nın 'Türkiye'de ilan edilen Özel Çevre Koruma Bölgesi $(\ddot{O C C K B})^{\prime}$ listesine bakıldığında ise 18 adet bölge bulunmaktadır (T.C. Çevre ve Şehircilik Bakanlığı, t.y.). Bu alanlar 'deniz kaplumbağalarının yumurtlama alanları ve Akdeniz Foklarmın yerleşim bölgeleri olmalarından dolayı biyolojik çeşitliliğin korunması' noktasında önemlidir (T.C. Çevre ve Şehircilik Bakanlığı, 2016, s. 206). Harita 4 incelendiğinde bu alanlar kırmızı renklerde gösterilmektedir. Şekil 3'te de görüldüğü üzere ilan tarihine göre sırasiyla bu bölge isimleri: 
Gökova (1988), Köyceğiz-Dalyan (1988), Fethiye-Göcek (1988), Tuz Gölü (1990), Patara (1990), Kaş-Kekova (1990), Göksu Deltası (1990), Belek (1990), Foça (1990), Datça-Bozburun (1990), Pamukkale (1990), Gölbaşı (1990), Ihlara (1990), Uzungöl (2004), Saros Körfezi (2010), Finike Deniz Altı Dağları (2013), Salda Gölü (2019) ve Karaburun-Ildır Körfezi (2019)'dir. Her bölgenin ilan tarihi, 1988 yılından itibaren, geniş bir zaman diliminde gerçekleşerek günümüze kadar gelmiştir (T.C. Çevre ve Şehircilik Bakanlığı, t.y).

Şekil 3. İlan Edilme Tarihine Göre Özel Çevre Koruma Bölgeleri (T.C. Çevre ve Şehircilik Bakanlığı'nın sitesinden faydalanılarak hazırlanmıştır

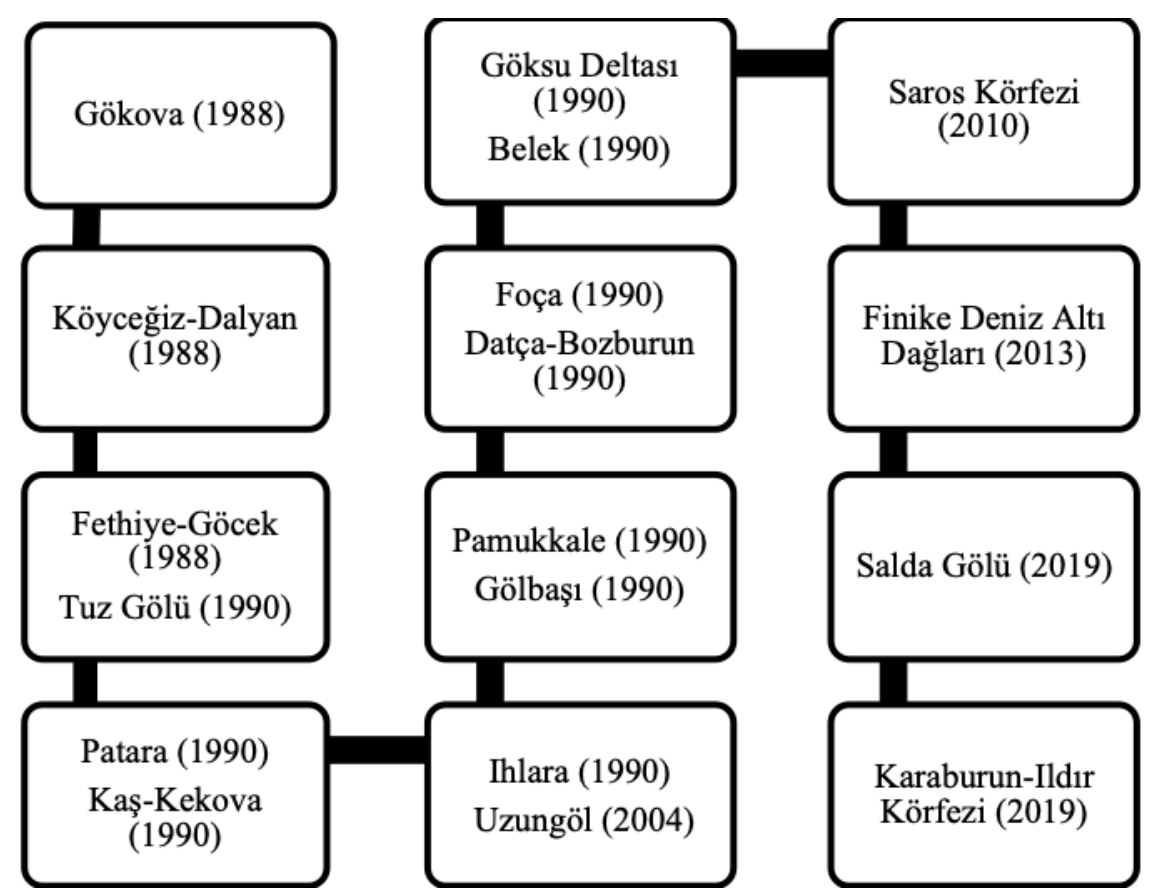

Harita 4. Türkiye'de Yer Alan Özel Çevre Koruma (ÖÇK) Bölgeleri (T.C. Çevre ve Şehircilik Bakanlığı, t.y.)

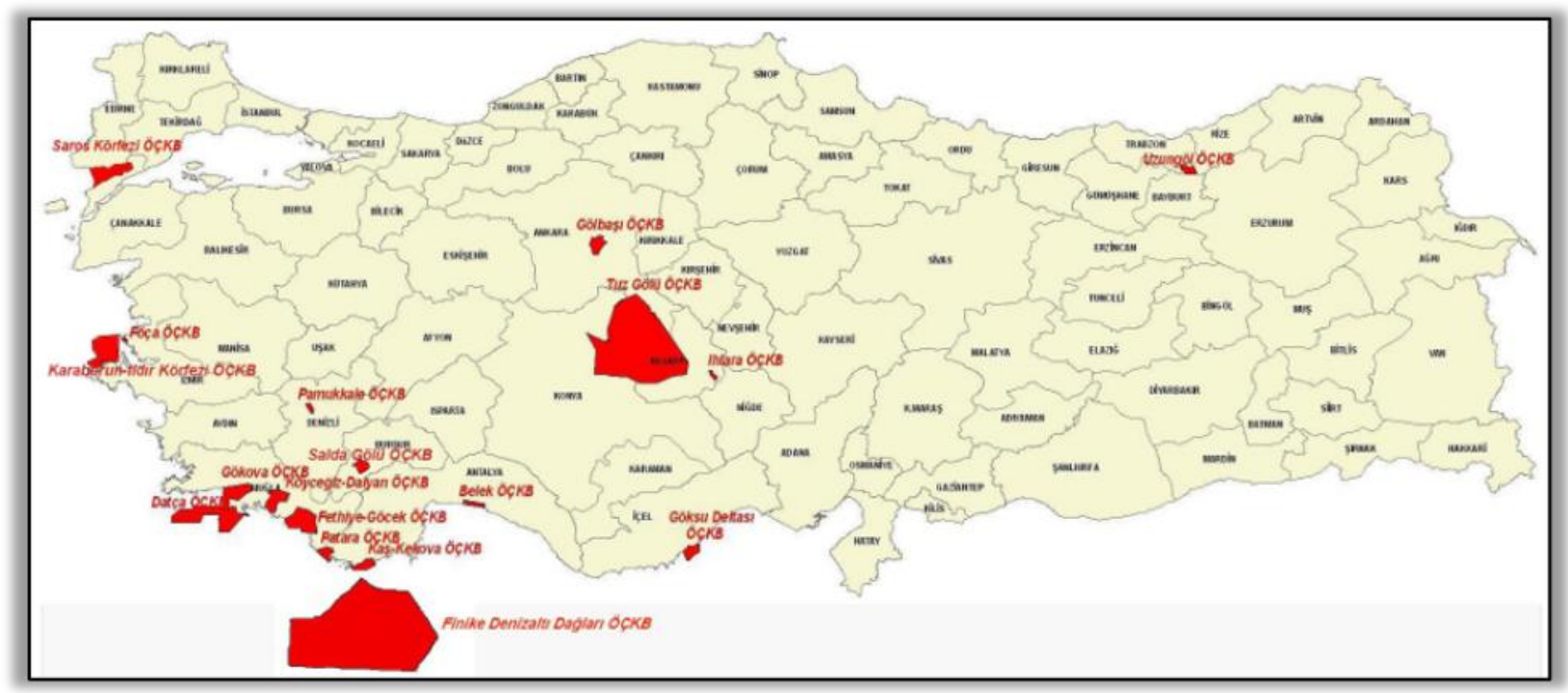

Bu ÖÇK bölgelerinin toplam alanı $25.829 .68 \mathrm{~km}^{2}$ dir. Türkiye'nin yüzölçümü ise 779.452 km²dir. Grafik 1 incelendiğinde Türkiye'de yer alan koruma alanlarını, Türkiye'nin yüzölçümüne oranladığımızda ÖÇK alanı \%3'lük dilimi kapsamaktadır. 
Grafik 1. Türkiye'de Yer Alan Özel Koruma Alanları Oranı ve ÖÇKB Alanları Dışındaki Yerlerin Oranı (T.C. Çevre ve Şehircilik Bakanlığının sitesinden faydalanılarak hazırlanmıştır)

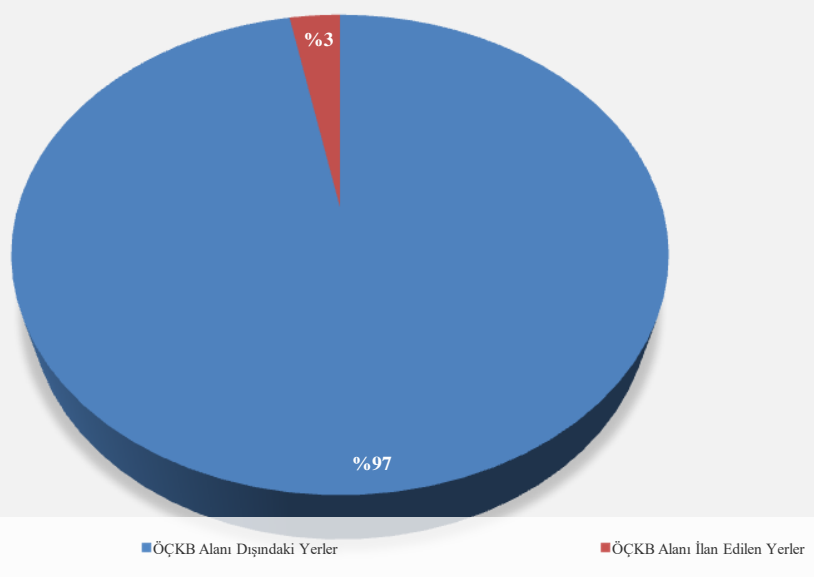

Bölgenin yüzölçümlerinin büyüklüğüne göre Türkiye'de yer alan koruma alanının yüzdelik değeri değişmektedir. ÖÇKB alanının \%3'lük dilimini Grafik 2'de incelendiğinde, Türkiye'deki ÖÇKB'nin en büyük payını Finike Deniz Altı Dağları ve Tuz Gölü oluşturduğu görülmektedir (T.C. Çevre ve Şehircilik Bakanlığı, t.y.).

Grafik 2. Türkiye'de Yer Alan Özel Koruma Alanları (T.C. Çevre ve Şehircilik Bakanlığı'nın Çevre Durum Raporundan (2016, s. 214-220) faydalanılarak hazırlanmıştır)

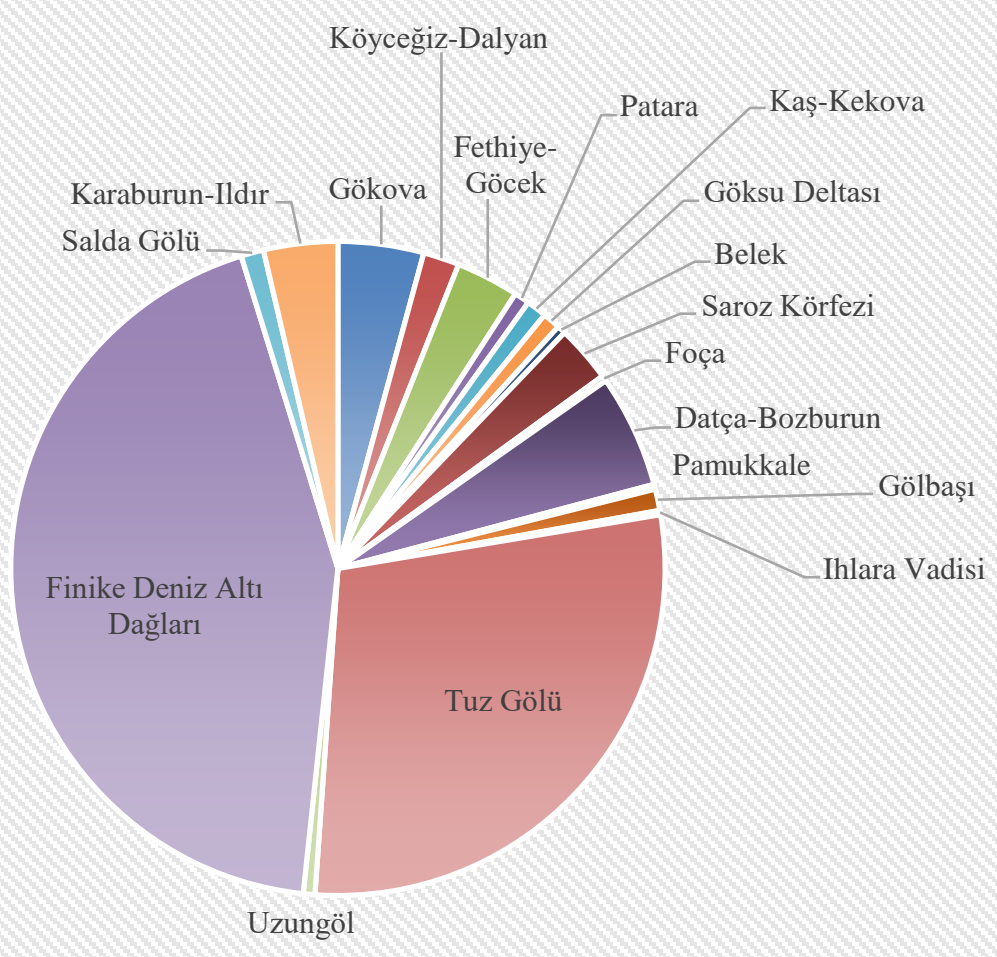

- Gökova

- Köyceğiz-Dalyan

- Fethiye-Göcek

- Patara

- Kaş-Kekova

- Göksu Deltas1

- Belek

- Saroz Körfezi

- Foça

- Datça-Bozburun

- Pamukkale

- Gölbaşı

- Ihlara

- Tuz Gölü

- Uzungöl

- Finike

2873 sayılı Milli Parklar Kanunu kapsamında bakıldığında ise; Türkiye'de, 'Milli Park, Tabiatı Koruma Alanı, Tabiat Parkı ve Tabiat Anıtı Koruma Alanları' bulunmaktadır. Bu bağlamda, 2015 yılından itibaren 40 Milli Park, 31 adet Tabiatı Koruma Alanı, 112 Tabiat Anitı ve 2016 yılından 
itibaren de 208 adet Tabiat Parkı Türkiye' de yer almaktadır (T.C. Çevre ve Şehircilik Bakanlığı, 2016, s. 204-206).

Diğer taraftan, Akdeniz'de Keşiş Foklarının korunması için bölge çapında geliştirilen bir stratejik plan çerçevesinde havzadaki ülkelerin performanslarına bakıldığında Harita 5 'te, bu ülkelerin plana ilişkin yükümlülüklerini yerine getirme sorumlulukları bağlamında farklı gruplara ayrıldığı görülür. Yeşil renkle gösterilen Grup A ülkeleri 2007 yılından sonra Keşiş Foku yetiştiriciliğinin rapor edildiği ülkeleri, Sarı renkle gösterilen Grup B ülkeleri Keşiş Foku varlığına ilişkin kanıtı olan ancak 2000 yılından sonra rapor bildirmeyen ülkeleri, Kırmızı renkle gösterilen Grup C ülkeleri ise 2000 yılından itibaren Keşiş Foku'nun rapor edilmediği ülkeleri göstermektedir. Çalışma kapsamında ele alınan ülkeler bağlamında bakıldığında; İspanya Grup B ülkeleri arasında yer alırken, Türkiye ise Grup A ülkeleri arasında yer almaktadır. Bu bağlamda, her ne kadar B Grubu ülkeler yaşayan Keşiş Foku alanlarına sahip olan ülkeler olarak önemli olsa da, A Grubu ülkelerin eylemin en etkin şekilde uygulandığ yerler olduğu ve türlerin hayatta kalması için en umutlu ve en elverişli grubu oluşturduğu ifade edilmektedir (UNEP/MAP, 2013, s. 88-89).

Harita 5. 2011 yılında ülkelere göre fok koruma statüsü (UNEP/MAP, 2013, s. 88)

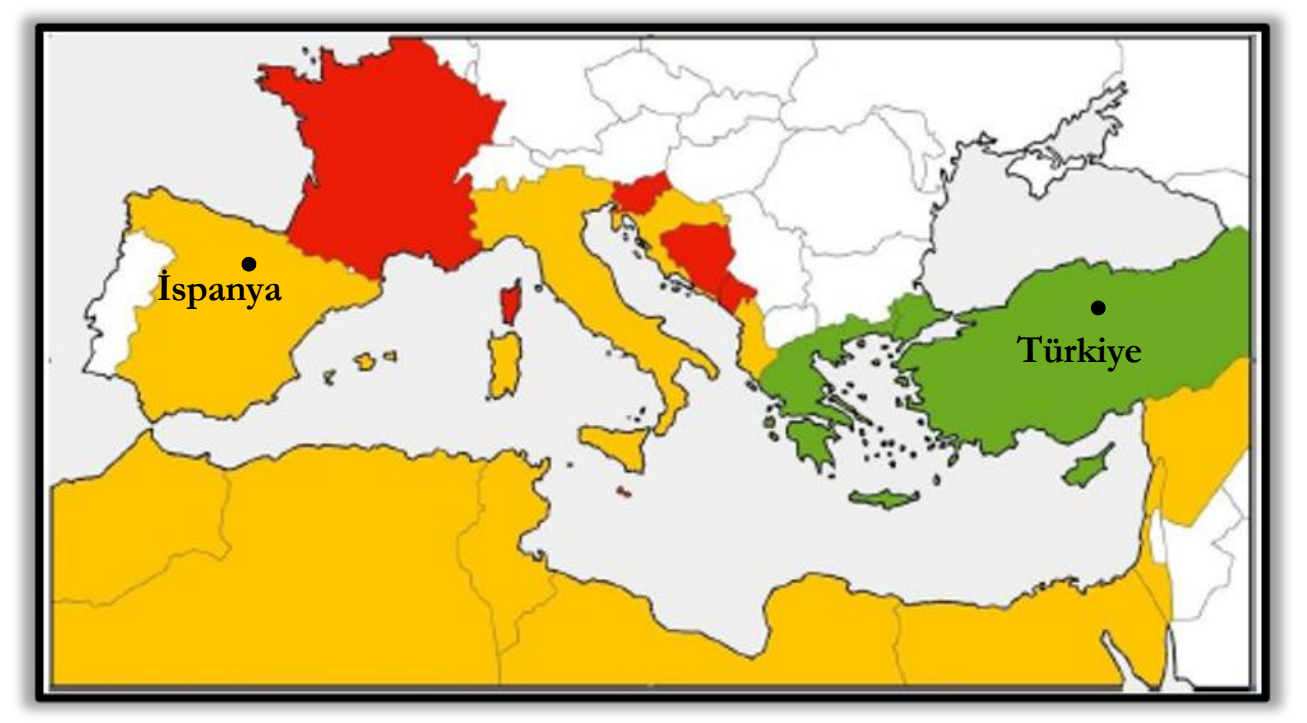

3-6 Aralık 2013'te iki yıl içinde alınan kararların tasdik edildiği '18. Taraf Ülkeler (COP18) Toplantısı (Ordinary Meeting Contracting Parties)' İstanbul'da gerçekleşmiştir. Bu toplantı sonucunda Barselona Sözleşmesi'nin '2014-2015 Dönem Başkanlı̆̆ı' Türkiye tarafından yürütülmüştür (UNEP, 2013). Çevre ve şehir kavramının ön planda olduğu 'İstanbul Deklarasyonu' yayınlanmıştır. Bu bağlamda Türkiye, kıyı kentlerin yerel yönetimlerle entagrasyonunun geliştirilmesi kapsamında, kıyı kentlere 'Çevre Dostu Şehirler Ödülü' fikrini sunmuş ve tasdik edilmiştir. Bu ödül düşüncesi, İstanbul Deklarasyonu' nun ana konularından biri olarak Barselona Sözleşmesi'nin kayıtlarına geçmiştir. Bu doğrultuda 9-11 Şubat 2016'da Yunanistan'da gerçekleşen COP19 toplantısında önemli kararlar alınmıştır. Toplantıda 'İstanbul Çevre Dostu Şehirler Ödülü (Istanbul Award)' görüşmeleri bitirilmiş ve ödülün iki yılda bir Akdeniz'e kıyısı olan ülkelerin şehirlerine bırakılmasına karar verilmiştir (T.C. Çevre ve Şehircilik Bakanlığı, 2020 ve UNEP, 2020). Bu şehirler aynı zamanda, iklim değişikliklerinin ve çevre konularının odağında bulunan kentlerdir (Türkiye Ulusal Rapor, 2014, s. 24). Türkiye 2016 'da, ödülün adının, sponsorluk vasıtasıyla bir Türk kentinin isminin verilmesi fikrini 
ortaya atmış ve bu ödül ilk kez Arnavutluk'ta COP20 toplantısında verilmiştir. İkinci kez ise Napoli'de olan COP21 toplantısında verilmiştir (T.C. Çevre ve Şehircilik Bakanlığı, 2020).

Yunanistan'ın Atina şehrinde gerçekleşen COP19 toplantısından sonra Türkiye, denizlerin istikbalinin teminat altına alınması, sürdürülebilirliğinin sağlanması, kirliliğin minimum seviyeye indirilmesi ve biyoçeşitliliğin muhafaza edilmesi gerektiği konusunda çalışmalar yapmaya başlamıştır. 'Sürdürülebilir Kalkınma Hedefi 14' çerçevesinde kirliliği önleme ve biyoçeşitliliği koruma boyutunda uygulamalar yapmıştır. Diğer yandan, ABD'de Haziran 2017' de gerçekleşen 'Birleşmiş Milletler Okyanuslar Konferansı'nda da kirlilik konusu ele alınmış, Türkiye, 'Deniz Çöpü Stratejik Eylem Planları'nın 2018 yılı sonuna kadar tüm kıyı kentlerinde uygulanması için gerekli her çalışmayı üstleneceğini dile getirmiştir. Bu kararını Ekim 2017' de Malta'da gerçekleşen 'Bizim Okyanuslarımız Konferansı'nda da yinelemiştir. 'Sürdürülebilir Kalkınma 2030 Gündemi' çevre konusunda atılan diğer önemli bir adım olmuştur. Türkiye uygulama sürecinde büyük bir çaba göstermiş ve doğa içinde etkisi geniş olan 'Geride Kimse Kalmayacak' ilkesini özümsemiştir (T.C. Çevre ve Şehircilik Bakanlığı, 2020).

Türkiye'de Akdeniz ve Karadeniz Bölgesi'nde çevre konuları hakkında kurulmuş olan komisyonlar birbiri ile işbirliği içindedir. Bu çalışmanın en güzel örneklerinden biri de, COP19 toplantısında 'Karadeniz Komisyonu Daimi Sekretaryasının' ve 'Barselona Sözleşmesi Sekretaryasının' imzaladığı ön anlaşmadır. Deniz çöpleri ve deniz kirliliği hakkında hazırlanan 'Deniz Çöpleri Eylem Plan ve Deniz Çöplerine İlişkin İzleme Kılavuzu' iki bölge komisyonunun kararlılığını göstermiştir (T.C. Çevre ve Şehircilik Bakanlığı, 2020). Türkiye'nin gerek stratejik konumu, gerekse; yerel, bölgesel ve küresel bağlamda uyguladığı stratejilerle, diğer ülkeler arasındaki önemini giderek arttırmaktadır. Akdeniz Havzası'ndaki bu bölgesel çalışma da Türkiye'ye önemli avantajlar sunmaktadır (Mehter Aykın, 2000, s. 121). Barselona Sözleşmesi'nin 'sürdürülebilir kalkınma hedefleri doğrultusunda değiştirilerek' yeni bir güç sağlamasında Türkiye büyük ölçüde katkı sağlamıştır. Bu kapsamda, Akdeniz Sürdürülebilir Kalkınma Komisyonu Türkiye'nin öncülüğünde oluşturulmuştur (Algan, 2011, s. 52).

\section{SONUÇ}

Medeniyetlerin buluştuğu Akdeniz; jeo-stratejik ve jeo-politik kapasitesi ile ticaret ve enerji ağlarının önemli odaklarından birini oluşturmaktadır. Bölge, küresel ölçüde gerek deniz taşımacılığındaki rolü, gerekse sanayi ve ticaretin yoğunlaştığı çekim merkezi olmasıyla hep anahtar rolünde olmuştur. Öyleki son zamanlarda, Doğu Akdeniz Havzası'nda keşfedilen petrol ve doğalgaz rezervleri enerji noktasında bölgenin değerini yeniden gündeme getirmiştir. Günümüzde yaşanılan enerji taşımacılı̆̆ı, sanayileşme ve kontrolsüz büyüme gibi etkenler, bölgenin ekolojik yapısına karşı tehdit oluşturmaktadır. Akdeniz havzası bu tehditten bazen bölgesel boyutta bazense ulusal boyutta etkilenmiş, bu çevresel tehdit kendini daha çok petrol ve türevlerinin taşınması sırasında oluşan deniz kazalarında göstermiştir. Kazalar sonucunda kirlilik ciddi boyutlara ulaşmıştır. Bölgenin çevresel bağlamda korunması için paydaşlar birlikte hareket etmiş, Stockholm Konferansı'ndan itibaren başlayan bu süreci paydaşlar iyi yönetmeye çalışmışlardır. Bu bağlamda; çok çeşitli sayıda işbirlikleri, bölgesel eylem planları, anlaşmalar ve örgütlenmeler gerçekleştirilmiştir.

$\mathrm{Bu}$ zengin havzanın korunması için yapılan işbirliklerinden biri olan ve 1976'da imzalanan Barselona Sözleşmesi, resmi adıyla Akdeniz'in Kirliliğe Karşı Korunması Sözleşmesi'dir. Akit, 1975 yılında imzalanan Akdeniz Eylem Planı'nın hukuki boyutunu oluşturmasının yanı sıra UNEP Bölgesel Deniz Programlarının da en önemli örneğini meydana getirmiştir. Havzadaki 
faaliyetlerin yürütülmesindeki önemli organlardan biri olan akit, Akdeniz'deki deniz kirliliğinin önlenmesi ve biyoçeşitliliğin muhafaza edilmesinde önemli katkılar sağlamıştır. Akdeniz kıyıları ile ilgili olarak gelecek çalışmalara yön vermesi de sözleşmeyi değerli kılmaktadır. Sözleşme kapsamında bulunan yedi protokol, çevre sorunlarına farklı perspektiften baktığı için her protokolün paydaşı da farklı olmaktadır. Protokollerin gayesi Akdeniz Havzasında meydana gelen ve taşıtlardan kaynaklanan kirliliğin önlenmesi, özel koruma alanlarının oluşturulması ve biyoçeşitliliğin muhafaza edilmesidir. Protokoller, bazen bölgedeki kara kökenli kirliliği engellemeye çalışırken bazen de tehlikeli atıkların bertaraf edilmesini sağlamakta, bu bağlamda aslında bir ölçüde havzanın farklı meselelerine çözüm aramaktadırlar. Türkiye bu sözleşme protokollerinden sadece Açık Deniz Protokolüne ve Bütünleşik Kıyı Alanları Yönetimi Protokolüne taraf değildir.

İspanya çevrenin ve habitatın korunması konusunu hem bölgesel hem de ulusal boyutta önemsemiştir. Bu çabası Barselona Sözleşmesi kapsamında da gözlemlenmiştir. Barselona Sözleşmesi'nin “Akdeniz'de Özel Koruma Alanları ve Biyolojik Çeşitliliğe İlişkin (SPA/BD) Protokolü" kapsamında Akdeniz Özel Koruma Alanları listesine bakıldığında 35 koruma alanından İspanya'nın 8 özel koruma alanı bulunmaktadır. Koruma alanları belirlenirken tarafların değerlendirme kriterlerine göre listeye karar verilmektedir. Aynı zamanda İspanya birçok Milli Parkına, Habitat Parkına, Tabiat Anıtına ve deniz rezervine sahip bulunmaktadır. İspanya, bu koruma alanlarını ve rezervlerini güncel olarak yenileyerek bakanlığının sitesinde halka sunmaktadır.

Türkiye'nin Akdeniz özelinde yaptığı çalışmalara bakıldığında ise; denizlerde oluşan kirliliğin önlenmesi konusunda geliştirilecek politikaların şekillenmesine katkı sağlayan ölçüm ve analizler yaptığı görülmektedir. Aynı zamanda elde edilen bu veriler her iki yılda bir Barselona Sözleşmesi Sekretaryası'na raporlanmaktadır. Bu bağlamda çevre kirliliği Türkiye'nin uluslararası alanda önem verdiği bir konu haline gelmiştir. Bu perspektifte hazırlanan, gerek bölgesel gerek ulusal boyuttaki uluslararası sözleşmelere taraf olmuştur. Türkiye, çevre korumasının değerinin ve sorumluluğun bilincinde olan bir ülkedir. Akdeniz Havzası özelinde önemli pozisyonda olan Barselona Sözleşmesi'nin de hem taraf ülkesidir hem de sözleşmenin odak noktasında yer almaktadır. Fakat çevrenin korunması için atılan adımlarda öncü konumunda bulunduğu halde SPA/BD Protokolü kapsamında oluşturan UNEP Akdeniz Özel Koruma Alanları listesine bakıldığında dokuz ülkenin koruma alanı bulunurken Türkiye'nin koruma alanı bulunmamaktadır. T.C. Çevre ve Şehircilik Bakanlığı'nın yayınladığı, Türkiye'de yer alan Özel Çevre Koruma Bölgesi (ÖÇKB) listesi gözden geçirildiğinde ise 18 adet koruma bölgesi bulunmaktadır. Bu koruma bölgelerinin alanını Türkiye'nin yüzölçümü alanına oranladığımızda ülkenin \%3’lük dilimi ÖÇK alanını kapsamaktadır. Aynı zamanda Türkiye'de de çok sayıda Milli Park ve Tabiat Parkı yer almaktadır. Hem İspanya'nın hem Türkiye'nin biyoçeşitlilik ve koruma alanları noktalarına önem verdiği gözlemlenmiştir. Örneğin Akdeniz'de Keşiş Foklarının Korunması için bölge çapında geliştirilen strateji planını incelendiğinde Türkiye ve İspanya'nın farklı gruplarda yer almasına rağmen iki ülkenin de başarılı bir konumda olduğu ancak Türkiye'nin daha iyi durumda olduğu söylenebilir.

Türkiye, Akdeniz Havzası'nda kirliliği önleme ve biyoçeşitliliği muhafaza etme konusunda yaptığ1 çalışmalarla 1976 yılından itibaren önemli nitelikte yol almıştır. Barselona Sözleşmesi'nin belirlemiş olduğu hedefler doğrultusunda uluslararası platformda yardımlar sağlamış ve bu ölçüde çalışmalar da yapmıştır. Ancak bu çabaların daha etkin ve verimli bir 
çevre politikası ve uygulamalarına dönüşebilmesi için daha çok çabaya gerek duyulmaktadır. $\mathrm{Bu}$ bağlamda öncelikle, hukuk sistemi kapsamında, çevre hukukunun ve bilincinin küresel ölçekte yaygınlaşması son derece önemlidir. Benzer şekilde, çevre sorunlarına çözüm geliştirme konusunda yapılan işbirliği çalışmaları sadece havza ya da kıyı ülkelerine yönelik planları içermemelidir. Çünkü günümüzde çevre sorunları sınır aşan bir boyuta ulaşmış durumdadır. Kirliliğin önlenmesinde teknolojinden de en üst düzeyde istifade edilebilir. Bu bağlamda havza sorunları yapay zeka ortamında nicel ve nitel verilerin bütünleşik olarak analizleri yapılarak, riskler ve buna uygun alternatifli en uygun eylem planları oluşturulabilir. Bu çerçevede, yapay zeka kullanan bir politika geliştirme merkezi kurulabilir. Ayrıca, çevre olgusunun yerelleştirilmesi ve bilincin arttırılması için havza ülkeleri özelinde, gerek akademik düzeyde gerekse toplum kesimleri nezdinde çeşitli etkinlikler ve programlar yapılabilir. Diğer taraftan, STK'larla işbirliği ise sözleşmenin etkinliğinin arttırılmasında anahtar misyonu yerine getirebilir. Bu yüzden havzada yer alan konu ile ilgili sivil inisiyatif, yönetişim ortamı sağlama adına daha çok çalışmalara dahil edilebilir. Kamu yönetimi disiplini bağlamında incelendiğinde, Kara Kökenli Kirlilik Protokolü öncülüğünde, havzada oluşabilecek kirlilik için; bölgedeki kentleşme, endüstrileşme, tarım ve balıkçılık arasındaki ilişkinin sürdürülebilirliğinin sağlanması için uzun erimli stratejik bir kıyı planı ve programı oluşturulabilir. Ayrıca, Entegre Kıyı Alanları Yönetimi Protokolü kılavuzluğunda ise çevre yönetimine daha çok önem verilebilir ve biyolojik çeşitliliğin korunması kapsamında alınacak önlemler bir bütünsel bakış içinde ele alınabilir. Sonuç olarak, biyoçeşitliliğin ancak yaşam alanlarının iyileştirilmesi ile sağlanabileceği ve biyoçeşitliliğin muhafazası sağlanırken tabiatın da korunması gerektiği anlayışı unutulmamalıdır.

\section{KAYNAKÇA}

Abdulhakimoğulları, E., Sezer, Ö. ve Akpınar, M. (2011). Küresel ulusal ve yerel düzeyde bir insan hakkı olarak çevre hakkının gelişimi. Süleyman Demirel Üniversitesi Sosyal Bilimler Enstitüsü Dergisi, 2(14), 61-88. 15 Mayı 2020 tarihinde https://dergipark.org.tr/en/pub/sbe/issue/23234/248080 adresinden erişildi.

Abdullahzade, C. (2009). Gemilerden kaynaklanan petrol kirliliği: Türk hukukundaki son gelişmelerin değerlendirilmesi. Ankara Üniversitesi Hukuk Fakültesi Dergisi, 58(4), 693710. 26 Nisan 2020 tarihinde http://static.dergipark.org.tr:8080/articledownload/6696/b717/8a26/imp-JA93TK42MN-0.pdf? adresinden erişildi.

Aksoy, M. (2016). Doğu Akdeniz enerji rekabeti (teknik rapor). Insani ve Sosyal Araştırma Merkezi, 1-15. 25 Nisan 2020 tarihinde https://insamer.com/tr/dogu-akdeniz-enerjirekabeti $366 . h \mathrm{html}$ adresinden erişildi.

Algan, N. (2011). Akdeniz eylem planı. Sürdürülebilir kalkınma ve Türkiye. Milletlerarası Hukuk ve Milletlerarası Özel Hukuk Bülteni, 17, 37-54. 1 Mayıs 2020 tarihinde http://dergipark.org.tr/tr/download/article-file/99516 adresinden erişildi.

Arat, G., Türkeş, M. ve Saner, E. (2002). Uluslararası sözleşmeler ön rapor, 2-29. Çevre ve sürdürülebilir kalkınma paneli. Vizyon 2023: Bilim ve Teknoloji Stratejileri Teknoloji $\begin{array}{lllll}\text { Öngörü } & \text { Projesi. } & 24 & \text { Nisan } & 2020 \\ \end{array}$ http://www.konsec.com.tr/Resources/Mevzuat/UluslararasiSozl/CEVRE VE SURDUR ULEBILIR KALKINMA PANELI.pdf adresinden erişildi. 
Atmaca, M., Akkiprik, A., Aktoklu, E., Demirsoy, A., Doğanlar, M., Ergün, N.,... ve Yolcu, H. (2006). Hatay'da 10 sicak gün, korunan alanlar ve koruma statüleri. 22-25. Y. Ergün (Yay. haz.). Hatay: Mustafa Kemal Üniversitesi Yayın. 31 Mayıs $2020 \quad$ tarihinde http://doczz.biz.tr/doc/107455/hatay-da-on-sicak-g\%C3\%BCn--edi\%CC\%87t\%C3\%B6rya \%C5\%9Far-erg\%C3\%BCn- adresinden erişildi.

Baykal, H. ve Baykal, T. (2008). Küreselleşen dünyada çevre sorunları. Mustafa Kemal Üniversitesi Sosyal Bilimler Enstitüsü Dergisi, 5(9), 1-15. 28 Nisan 2020 tarihinde http://static.dergipark.org.tr:8080/articledownload/imported/1038000510/1038000299.pdf? adresinden erişildi.

Budak, S. (t.y.). Çevre politikası ve hukuku. İstanbul: İstanbul Üniversitesi Açık ve Uzaktan Eğitim Fakültesi Kamu Yönetimi Lisans Programı Kaynak Yayını. İstanbul Üniversitesi Açık ve Uzaktan Eğitim Fakültesi. 28 Nisan 2020 tarihinde https://yokdersleri.yok.gov.tr/\#ders adresinden erişildi.

Büyükgüngör, H. (2006). Çevre kirliliği ve çevre yönetimi. Toprak İşveren Dergisi, 1-15. 28 Nisan $2020 \quad$ tarihinde $\quad$ http://dosya.toprakisveren.org.tr/makale/2006-72hanifebuyukgungor.pdf adresinden erişildi.

Chauhan, B.S. (2008). Environmental studies. Delhi: Univercity Science Press. 28 Nisan 2020 tarihinde

https://books.google.com.tr/books?id=Pw6WiYiHPhIC\&printsec=frontcover\&dq=envir onment+studies\&hl=tr\&sa=X\&ved=0ahUKEwj23MuysJbpAhVLxMQBHYL8DQkQ6AE

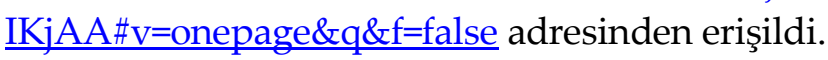

Çevre Kanunu (1983). (Say1: 2872). $24 \quad$ Nisan 2020 tarihinde https://www.mevzuat.gov.tr/MevzuatMetin/1.5.2872.pdf adresinden erişildi.

Dobson, A. (2016). Ekolojizm. (C. Yücel, Çev.). İstanbul: Yeni İnsan Yayınevi. 26 Ekim 2020 tarihinde https://www.academia.edu/24837079/Ekolojizm Andrew Dobson adresinden erişildi.

Englehardt, J. P. (1990). The strategic importance of the Mediterranean. 1-29. 1 May1s 2020 tarihinde https://apps.dtic.mil/dtic/tr/fulltext/u2/a223276.pdf adresinden erişildi.

EtimolojiTürkçe (2020). Çevre kelime kökeni. 8 Mayıs 2020 tarihinde https://www.etimolojiturkce.com/kelime/\%C3\%A7evre adresinden erişildi.

EUR-Lex (2014, 21 Şubat). The offshore protocol helps protect the Mediterranean Sea from pollution. 14 Mayis 2020 tarihinde https://eur-lex.europa.eu/legalcontent/EN/TXT/?uri=LEGISSUM:20060401 1, adresinden erişildi.

Güler, Ç. ve Çobanoğlu, Z. (2001). Çevresel etki değerlendirmesi. Ankara: Çevre Sağlığı Temel Kaynak Dizisi.

Güneş, M. (2016). Avrupa Birliği'nin çevre ve enerji politikalarında Doğu Akdeniz gazının tehdit ve imkanları. Uluslararası Akdeniz'de çevresel güvenlik konferansı, 1, 79-100.

Güneş, Ş. (2001). Karadeniz'de çevresel işbirliği. 1992 Bükreş Sözleşmesi. Orta Doğu Teknik Üniversitesi Gelişme Dergisi, 28(3-4), 311-337. 2 Mayıs 2020 tarihinde http://www.cevreciyiz.com/Upload/Docs/CevreAkademisi/CevreKoruma/KAradenizd e\%20cevreselisbirligi makale.pdf adresinden erişildi. 
Gürkan, S. (2019). Küresel çevre sorunları ve Türkiye'de çevre eğitiminin durumu. Akademik Sosyal Araştırmalar Dergisi, 6(43), 525-537. 15 Mayıs 2020 tarihinde file:///C:/Users/TOSHIBA/Downloads/sobidermakale.pdf adresinden erişildi.

Güven, K.C., Öztürk, B., Ergin, M., Balkıs, N., Algan, O., Topçuoğlu, ve Gezgin, T. (2005). Deniz kirliliği analiz yöntemleri iloili uluslar arası sözleşmeler. İstanbul: Türk Deniz Vakfı Yaymları. $\quad 1 \quad$ Mayis $2020 \quad$ tarihinde $\quad \underline{\text { http://tudav.org/wp- }}$ content/uploads/2018/04/deniz kirliligi.pdf adresinden erişildi.

Hilal, E. ve Doğan, B. (2018). Çevre kirliliği ve çevre duyarlılı̆̆ı. 98-121. Disiplinlerarası çevre araştırmaları içinde. Türkiye: İKSAD.

Humphrey, S. ve Lucas, S. (2015). Outcome evaluation of Barcelona convention/ United Nations Environment Programme - Mediterranean Action Plan (UNEP-MAP) five year programme of work 2010-2014. Evaluation Office. 2 Mayis 2020 tarihinde https://wedocs.unep.org/bitstream/handle/20.500.11822/273/Outcome Evaluation of B arcelona Convention UNEP MAP Five Year Programme of Work 2010-

2014.pdf? sequence $=1 \&$ isAllowed $=y$ adresinden erişildi

InforMEA (2011, 27 Ekim). Hazardous wastes protocol. 14 May1s 2020 tarihinde https://www.informea.org/en/treaties/hazardous-wastes-protocol adresinden erişildi.

Kara, H. (2004). Uluslararası sözleşmeler ve Türk hukukuna göre gemilerin sebep olduğu deniz kirliliği zararlarından hukuki sorumluluk. Yayımlanmamış doktora tezi, Marmara Üniversitesi, $\begin{array}{lllll}\text { İstanbul. } & 8 & \text { Mayis } & 2020 & \text { tarihinde }\end{array}$ https://katalog.marmara.edu.tr/eyayin/tez/T0050371.pdf adresinden erişildi.

Kaya, Y. (2011). Çok taraflı çevre anlaşmalarına uyum sorunu ve Türkiye üzerine bir değerlendirme. Süleyman Demirel Üniversitesi İktisadi ve İdari Bilimler Fakültesi Dergisi, 16(2), $\quad 439-462 . \quad 25 \quad$ May1s $2020 \quad$ tarihinde http://www.acarindex.com/dosyalar/makale/acarindex-1423912722.pdf adresinden erişildi.

Kaypak, Ş. (2012). Çevre hukukunun ulusal ve uluslararası boyutları. Adıyaman Üniversitesi Sosyal Bilimler Enstitüsü Dergisi, 5(10), 205-242. 1 Mayı 2020 tarihinde https://dergipark.org.tr/en/download/article-file/15195 adresinden erişildi.

Kaypak, Ş. (2012). Güvenlikte yeni bir boyut; çevresel güvenlik. Ekonomik ve Sosyal Araştırmalar Dergisi, $\quad 8, \quad 1-22 . \quad 3 \quad$ May1s 2020 tarihinde https://www.academia.edu/29269436/G\%C3\%BCvenlikte_Yeni_Bir_Boyut \%C3\%87evr esel G\%C3\%BCvenlik adresinden erişildi.

Kılıç, S. (2001). Uluslararası çevre hukukunun gelişimi üzerine bir inceleme. C.Ü. İktisadi ve İdari Bilimler Dergisi, 2(2), 131-148. 3 Mayıs 2020 tarihinde http://eskidergi.cumhuriyet.edu.tr/makale/123.pdf adresinden erişildi.

Legambiente and the Civil Protection Department (May1s 2007). Report drawn up within clean up the Med 2007. Pollution from hydrocarbons in the Mediterranean Sea. 11 May1s 2020 tarihinde

https://www.legambiente.it/sites/default/files/docs/dossier_petrolio_en_0000000441.pdf adresinden erişildi. 
López Ornat, A. (2014). Akdeniz'de deniz ve kıyı koruma alanlarının oluşturulması ve yönetilmesi için rehber. MedMPA Akdeniz Bölgesi'ndeki Deniz ve Kıyı Koruma Alanlarının Geliştirilmesi Bölgesel Projesi. $26 \quad$ Mayı 2020 tarihinde https://www.tr.undp.org/content/turkey/tr/home/library/environment energy/director $\mathrm{y}$-for-establishing-and-managing-sea-protection-areas-in-.html adresinden erişildi.

Mehter Aykın, S. (2000). Akdeniz Havzası' nda barış, istikrar ve refahın sağlanmasına yönelik bir bölgesel işbirliği önerisi: turizm endüstrisinde Pan-Akdeniz ideali. Anatolia: Turizm Araştırmaları Dergisi, 11, 107-123. 1 Haziran 2020 tarihinde https://dergipark.org.tr/tr/pub/atad/issue/53028/701976 adresinden erişildi.

Milletlerarası Andlaşma (2002, 22 Ağustos). T.C. Resmi Gazete (Sayı: 24854). 10 Mayıs 2020 tarihinde https://www.resmigazete.gov.tr/eskiler/2002/08/20020822.htm adresinden erişildi.

Ministerio De Agricultura, Pesca y Alimentacion,Gabierno de España (t.y.). Reservas marinas de España. 26 Mayıs 2020 tarihinde https://www.mapa.gob.es/es/pesca/temas/proteccionrecursos-pesqueros/reservas-marinas-de-espana/isla-de-tabarca/caracteristicas/ adresinden erişildi.

Myerson, G. ve Rydin, Y. (1996). The language of environment: A new rhetoric. Oxon: Routledge. 3 Mayis

tarihinde https://books.google.com.tr/books?id=BJ8AAwAAQBAJ\&pg=PA37\&dq=environment+ word\&hl=tr\&sa $=$ X\&ved=0ahUKEwiBgezRypbpAhWtlIsKHRhxADAQ6AEIOzAC\#v=0 nepage\&q\&f=false adresinden erişildi.

Online Etymology Dictionary (2020). Environment. 8 May1s 2020 tarihinde https://www.etymonline.com/search?q=environment adresinden erişildi.

Özoğuz, Y. (2005). Akdeniz ülkelerinde atık suların etkili yönetimi, işlenişi ve tekrar kullanımı. Avrupa Birliği fon destekli proje, 3-50. 5 Mayıs 2020 tarihinde_https://cgi.tuharburg.de/ awwweb/wbt/emwater/documents/summary turkish.pdf adresinden erişildi.

Paker, H. (2012). Çevre rejimleri ve Türkiye'de sivil toplum örgütlerinin rolü: Akdeniz'de sürdürülebilirlik. Marmara Avrupa Araştırmaları Dergisi, 20(1), 151-175. 7 Mayıs 2020 tarihinde

http://dspace.marmara.edu.tr/bitstream/handle/11424/3670/6.pdf?sequence=1\&isAllow $\underline{\text { ed }=y}$ adresinden erişildi.

Regional Activity Center/Specially Protected Areas (RAC/SPA) (2010). Signatures and ratifications of the Barcelona Convention and the SPA/BD Protocol as at april 2010. 26 May1s 2020 tarihinde

https://www.racspa.org/sites/default/files/signatures_ratification_bc spabd.pdf adresinden erişildi.

RAC/SPA (2011). SPA/BD Protokolün ek 2'sinde listelenen kuş türlerinin korunması için eylem planı. 7-41. $26 \quad$ Mayis $2020 \quad$ tarihinde http://dcm.dka.gov.tr/App Upload/7.KUS EYLEM PLANI.pdf adresinden erişildi.

RAC/SPA (2017). Specially Protected Areas of Mediterranean Importance (SPAMIs). 26 May1s 2020 tarihinde $\quad$ http://www.rac-spa.org/sites/default/files/doc spamis/spamis2018.pdf adresinden erişildi. 
RAC/SPA (2019, Temmuz). Report of the fourteenth meeting of SPA/BD thematic focal points. 1-15. 26 Mayis 2020 tarihinde https://www.racspa.org/nfp14/documents/01 working documents/wg 46128 en.pdf adresinden erişildi.

RAC/SPA (2020). The marine biodiversity centre at the service of the Mediterranean countries. 26 Mayis $2020 \quad$ tarihinde https://www.racspa.org/sites/default/files/doc spa/brochure institutionelle.pdf adresinden erişildi.

RAC/SPA (Regional Activity Center for Specially Protected Areas) (2020). SPA/BD Protocol. 26 Mayıs 2020 tarihinde https://www.rac-spa.org/background adresinden erişildi.

Regional Activity Center (RAC) for SPA (2020). SPA/BD Protocol. 14 Mayıs 2020 tarihinde https://www.rac-spa.org/protocol adresinden erişildi.

Taze, F. ve Güneş, Y.(2012). Türkiye'de çevre ve doğal kaynaklar konusunda imzalanan uluslararası sözleşmelerin iç hukuka uyarlanmasında karşılaşılan sorunlar ve çözüm

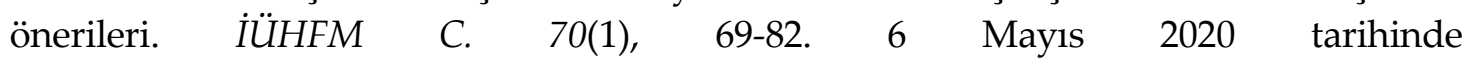
https://dergipark.org.tr/en/download/article-file/97702 adresinden erişildi.

T.C. Çevre ve Şehircilik Bakanlığı (t.y.). Özel çevre koruma. 4 Haziran 2020 tarihinde https://csb.gov.tr/sss/ozel-cevre-koruma adresinden erişildi.

T.C. Çevre ve Şehircilik Bakanlığı (t.y.). Özel çevre koruma bölgeleri harita. 4 Haziran 2020 tarihinde https://ockb.csb.gov.tr/ock-bolgeleri-harita-i-55 adresinden erişildi.

T.C. Çevre ve Şehircilik Bakanlığı (t.y.). Akdeniz'in deniz ortamı ve kıyı bölgelerinin korunması sözleşmesi (Barselona Sözleşmesi). (PowerPoint slayt). 27.04.2020 tarihinde Huri Eyüboğlu elektronik postasından Nahide Nur Falcıoğlu elektronik postasına iletilmek suretiyle temin edinilmiştir.

T.C. Çevre ve Şehircilik Bakanlığı (t.y.). Barselona ve Bükreş Sözleşmelerinin kara kökenli kirleticilere ilişkin yükümlülükleri. (PowerPoint slayt). 27.04.2020 tarihinde Huri Eyüboğlu elektronik postasından Nahide Nur Falcıoğlu elektronik postasına iletilmek suretiyle temin edinilmiştir.

T.C. Çevre ve Şehircilik Bakanlığı (2014, Aralık). Türkiye ulusal rapor (Türkiye Habitat III Ulusal Raporu). Ankara: T.C. Çevre ve Şehircilik Bakanlığı Kaynak Yayını. 1-55. Üçüncü Birleşmiş Milletler Konut ve Sürdürülebilir Yerleşmeler Konferansı. 30 Mayıs 2020 tarihinde

https://webdosya.csb.gov.tr/db/habitat/editordosya/file/HABITAT III ULUSAL RAPO

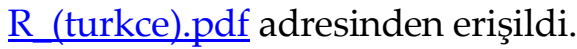

T.C. Çevre ve Şehircilik Bakanlığı_(2016, Aralık). Türkiye çevre durum raporu. Ankara: Çevre Envanteri ve Bilgi Yönetimi Dairesi Başkanlığı Kaynak Yayını. Çevresel etki değerlendirmesi izin ve denetim genel müdürlüğü. 1 Haziran 2020 tarihinde https://webdosya.csb.gov.tr/db/ced/editordosya/tcdr tr 2015.pdf adresinden erişildi.

T.C. Çevre ve Şehircilik Bakanlığı (2020). Çevre ve şehircilik alanında taraf olunan uluslararası protokoller. 13 Mayıs 2020 tarihinde https://ab.csb.gov.tr/sozlesmeler-i-98916 adresinden erişildi. 
T.C. Çevre ve Şehircilik Bakanlığ https://webdosya.csb.gov.tr/db/bolu/icerikler/cevre-20180222082618.pdf adresinden erişildi.

T.C. Dişişleri Bakanlı̆̆1 (2020). Barselona sözleşmesi. 23 Nisan 2020 tarihinde http://www.mfa.gov.tr/barselona-sozlesmesi.tr.mfa adresinden erişildi.

Tuna, M. (2011). Çevresel sorunların küreselleşmesi. Muğla Üniversitesi SBE Dergisi, 1(2), 1-13. 27 Nisan $2020 \quad$ tarihinde $\quad$ http://static.dergipark.org.tr:8080/articledownload/31a6/df13/2e4e/imp-JA53MH66UT-0.pdf? adresinden erişildi.

Türk Dil Kurumu (2020). Çevre. 8 Mayıs 2020 tarihinde_https://sozluk.gov.tr/ adresinden erişildi.

Türk Dil Kurumu (2020). Çevre kirliliği. 8 Mayıs 2020 tarihinde https://sozluk.gov.tr/ adresinden erişildi.

Türkiye Barolar Birliği (2014). Uluslararası çevre koruma sözleşmeleri. Ankara: Türkiye Barolar

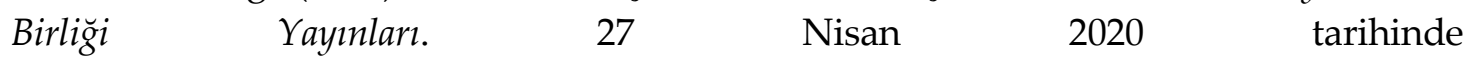
http://tbbyayinlari.barobirlik.org.tr/TBBBooks/472.pdf adresinden erişildi.

UNEP (t.y.). Convention for the protection of the Mediterranean Sea against pollution. 13 May1s 2020 tarihinde http://wedocs.unep.org/bitstream/id/53143/convention eng.pdf adresinden erişildi.

UNEP (t.y.). Status of signatures and ratifications of the Barcelona Convention and its protocols. 13 Mayis 2020 tarihinde http://wedocs.unep.org/bitstream/id/7f04ff0f-8108-40d5-be9addc95bab248d/StatusOfSignaturesAndRatifications_20190424.doc adresinden erişildi.

UNEP (t.y.). Protocol for the prevention and elimination of pollution of the Mediterranean Sea by dumping from ships and aircraft or incineration at sea, 22-27. 14 May1s 2020 tarihinde http://wedocs.unep.org/bitstream/id/53220/consolidated dumping eng.pdf adresinden erişildi.

UNEP (t.y.). ICZM Protocol, PAP/RAC. 14 Mayis 2020 tarihinde http://paprac.org/iczm-protocol adresinden erişildi.

UNEP/MAP (2013, 16 Aralık). Report of the $18^{\text {th }}$ ordinary meeting of the countries parties. Athens. 31 Mayis 2020 tarihinde http://racspa.org/nfp12/documents/reference/13ig21 9 eng.pdf adresinden erişildi.

UNEP (2017, 16 Ağustos). Success story: Mediterranean. 25 Nisan 2020 tarihinde https://www.unenvironment.org/news-and-stories/speech/success-story-mediterranean adresinden erişildi.

UNEP (2017, 19 Ekim). Emergency Protocol / Prevention and Emergency Protocol. 14 May1s 2020 tarihinde $\quad$ https://web.unep.org/unepmap/3-emergency-protocol-prevention-andemergency-protocol adresinden erişildi.

UNEP (2017, 19 Ekim). Barcelona Convention and amendments. 25 Nisan 2020 tarihinde https://web.unep.org/unepmap/1-barcelona-convention-and-amendments adresinden erişildi. 
UNEP (2017, 19 Ekim). Specially Protected Areas Protocol / SPA and Biodiversity Protocol. 26 May1s 2020 tarihinde https://web.unep.org/unepmap/5-specially-protected-areas-protocolspa-and-biodiversity-protocol adresinden erişildi.

UNEP (2019, 24 Nisan). Coordinating unit for the Mediterranean action plan secretariat to the Barcelona Convention and its protocols. 25 Nisan 2020 tarihinde https://web.unep.org/unepmap/contracting-parties/adresinden erişildi.

UNEP (2020). What is our pollution or LBS Protocol? 14 Mayis 2020 tarihinde http://cep.unep.org/cartagena-convention/lbs-protocol/protocol-concerning-pollutionfrom-land-based-sources-and-activities adresinden erişildi.

UNEP (2020). Mediterranean action plan. 25 Nisan 2020 tarihinde unenvironment.org/exploretopics/oceans-seas/what-we-do/working-regional-seas/regional-seas programmes/mediterranean adresinden erişildi.

UNEP (2020). UNEP/MAP Mid-Term strategy 2016-2021. 3 May1s 2020 tarihinde https://web.unep.org/unepmap/what-we-do/mid-term-strategy-2016-2021 adresinden erişildi.

UNEP (2020). COP (Contracting Parties). 31 Mayı 2020 tarihinde https://web.unep.org/unepmap/fr/document-keywords/cop adresinden erişildi.

U.S. Department of the interior,The office of water research and technology (1978). Selected Water Resources Abstracts. Field 5: Water Quality Management and Protection, 11(13), 7883. Washington, DC, A Semimonthly Publication. 29 Mayıs 2020 tarihinde https://books.google.com.tr/books?id=LDCMOKPEbyUC\&pg=RA1-PA78\&lpg=RA1PA78\&dq=The+Barcelona+convention+and+its+protocols adresinden erişildi.

Ünal, E. (2014). Torrey canyon deniz kazası ve sonuçları. 8 Mayıs 2020 tarihinde https://www.academia.edu/10807718/TORREY CANYON D\%C9\%99niz q\%C9\%99za s\%C4\%B1 TORREY CANYON Deniz Kazas\%C4\%B1 adresinden erişildi.

Yıldız, D. (2016). Akdeniz Havzası'nın hidrojeopolitiği ve Türkiye. Su Politikaları Kongresi, Ankara, 616-626. $\quad \underline{25}$ Nisan 2020 tarihinde http://www.imo.org.tr/resimler/ekutuphane/pdf/9163.pdf adresinden erişildi. 